\title{
Contemporary carotid imaging: from degree of stenosis to plaque vulnerability
}

\author{
Waleed Brinjikji, MD, ${ }^{1}$ John Huston III, MD, ${ }^{1}$ Alejandro A. Rabinstein, MD, ${ }^{2}$ \\ Gyeong-Moon Kim, MD, ${ }^{3}$ Amir Lerman, MD, ${ }^{4}$ and Giuseppe Lanzino, MD ${ }^{5}$
}

Departments of ${ }^{1}$ Radiology, ${ }^{2}$ Neurology, ${ }^{4}$ Cardiovascular Diseases, and ${ }^{5}$ Neurosurgery, Mayo Clinic, Rochester, Minnesota; and ${ }^{3}$ Department of Neurology, Samsung Medical Center, Sungkyunkwan University School of Medicine, Seoul, Korea

Carotid artery stenosis is a well-established risk factor of ischemic stroke, contributing to up to $10 \%-20 \%$ of strokes or transient ischemic attacks. Many clinical trials over the last 20 years have used measurements of carotid artery stenosis as a means to risk stratify patients. However, with improvements in vascular imaging techniques such as CT angiography and MR angiography, ultrasonography, and PET/CT, it is now possible to risk stratify patients, not just on the degree of carotid artery stenosis but also on how vulnerable the plaque is to rupture, resulting in ischemic stroke. These imaging techniques are ushering in an emerging paradigm shift that allows for risk stratifications based on the presence of imaging features such as intraplaque hemorrhage (IPH), plaque ulceration, plaque neovascularity, fibrous cap thickness, and presence of a lipid-rich necrotic core (LRNC). It is important for the neurosurgeon to be aware of these new imaging techniques that allow for improved patient risk stratification and outcomes. For example, a patient with a low-grade stenosis but an ulcerated plaque may benefit more from a revascularization procedure than a patient with a stable $70 \%$ asymptomatic stenosis with a thick fibrous cap.

This review summarizes the current state-of-the-art advances in carotid plaque imaging. Currently, MRI is the gold standard in carotid plaque imaging, with its high resolution and high sensitivity for identifying IPH, ulceration, LRNC, and inflammation. However, MRI is limited due to time constraints. CT also allows for high-resolution imaging and can accurately detect ulceration and calcification, but cannot reliably differentiate LRNC from IPH. PET/CT is an effective technique to identify active inflammation within the plaque, but it does not allow for assessment of anatomy, ulceration, IPH, or LRNC. Ultrasonography, with the aid of contrast enhancement, is a cost-effective technique to assess plaque morphology and characteristics, but it is limited in sensitivity and specificity for detecting LRNC, plaque hemorrhage, and ulceration compared with MRI.

Also summarized is how these advanced imaging techniques are being used in clinical practice to risk stratify patients with low- and high-grade carotid artery stenosis. For example, identification of IPH on MRI in patients with low-grade carotid artery stenosis is a risk factor for failure of medical therapy, and studies have shown that such patients may fair better with carotid endarterectomy (CEA). MR plaque imaging has also been found to be useful in identifying revascularization candidates who would be better candidates for CEA than carotid artery stenting (CAS), as high intraplaque signal on time of flight imaging is associated with vulnerable plaque and increased rates of adverse events in patients undergoing CAS but not CEA.

http://thejns.org/doi/abs/10.3171/2015.1.JNS142452

KEY WORDS carotid artery; MRI; ultrasound; risk; vascular disorders

ABBREVIATIONS AHA = American Heart Association; CAS = carotid artery stenting; CEA = carotid endarterectomy; CEUS = contrast-enhanced ultrasonography; CTA = CT angiography; DCE = dynamic contrast-enhanced; DSCT = dual-source CT; FDG = fluorodeoxyglucose; FSE = fast spin echo; Gd = gadolinium; HU = Hounsfield units; $\mathrm{IPH}=$ intraplaque hemorrhage; LRNC = lipid-rich necrotic core; MDCT = multidetector-row CT; MDCTA = MDCT angiography; MES = microembolic signal; MMP-9 = matrix metalloproteinase-9; MRA = MR angiography; PDW = proton density-weighted; SUV = standardized uptake value; SUVmax = maximal SUV; TBR = target-to-background ratio; TCD = transcranial Doppler ultrasonography; TIA = transient ischemic attack; TOF = time of flight; USPIO = ultrasmall superparamagnetic iron oxide.

SUBMITTED October 27, 2014. ACCEPTED January 20, 2015.

INCLUDE WHEN CITING Published online July 31, 2015; DOI: 10.3171/2015.1.JNS142452.

DISCLOSURE Dr. Lanzino reports being a consultant for Covidien. 
$\mathrm{C}$ AROTID artery stenosis is a well-established risk factor for ischemic stroke, contributing to $10 \%-20 \%$ of strokes or transient ischemic attacks (TIAs). ${ }^{28}$ Randomized clinical trials comparing medical therapy with surgical intervention have primarily selected patients by degree of stenosis. ${ }^{8,27,37,41,72,116}$ Because current guidelines have established degree of stenosis as the primary surrogate for stroke risk and indication of intervention, much research has been dedicated to determining sensitive, specific, and cost-effective techniques to accurately measure degree of stenosis. ${ }^{75}$

It has been known for many years that plaque stability and vulnerability are more important than degree of stenosis in determining the risk of acute coronary syndrome. It has been often said that the situation is different in the carotid arteries because they have much larger diameter and different hemodynamic conditions. Also, coronary arteries typically cause symptoms because of plaque rupture leading to thrombotic luminal occlusion, whereas carotid arteries characteristically cause symptoms by embolization without local vessel closure. However, as we will discuss, there is increasing evidence that active, unstable plaques in the carotid arteries are more prone to embolization, regardless of the degree of stenosis.

The inadequacy of limiting the assessment of carotid atherosclerosis to the degree of stenosis is also highlighted by clinical experience. Cryptogenic stroke, stroke with no definite cause despite extensive workup, occurs in up to $30 \%$ of patients with ischemic stroke. One-third of patients with cryptogenic stroke have nonstenotic (or producing mild or minimal stenosis) carotid atherosclerotic plaques ipsilateral to the stroke. ${ }^{32}$ On MRI, these plaques often demonstrate variable characteristics of vulnerable plaque, such as intraplaque hemorrhage (IPH), plaque rupture, and luminal thrombus. Thus, it is likely that a high proportion of these strokes are due to rupture or erosion of nonstenotic, high-risk plaques. ${ }^{32}$ Furthermore, many patients with a high degree of stenosis have stable plaques that are thought to be at low risk of rupture..$^{42}$ Because of such findings, over the last decade there has been a paradigm shift on the imaging-based risk stratification of carotid disease from static measurements of carotid artery stenosis to characterization of the dynamic biological processes occurring within carotid plaques. It is important for neurosurgeons to be aware of this paradigm shift as it allows for improved risk stratification of patients with both high- and low-degree carotid artery stenosis.

In this review article, we summarize current developments in imaging-based assessment of carotid plaques. We first discuss current paradigms in plaque biology and then review how various imaging modalities (CT, MRI, ultrasonography, and PET) can be used to characterize the pathological characteristics of plaques. We also discuss how these advanced imaging techniques are being used to monitor the effects of medical treatment and to identify ideal candidates for surgical and medical therapies.

\section{Plaque Histopathology}

Carotid plaque imaging hinges on the understanding of the histopathological characteristics of advanced athero- sclerotic disease. The American Heart Association (AHA) developed a well-validated criterion for histological classification of atherosclerotic plaque in 1995.100 The early process of atherosclerotic plaque formation involves isolated deposition of macrophages and foam cells (Type I), followed by a fatty streak lesion with mainly intracellular lipid accumulation (Type II) and then deposition of extracellular lipids within the plaque (Type III). This process occurs over the course of the first 3 decades of life and is clinically silent. ${ }^{99,101}$

The Type IV lesion, also known as an atheroma, is the first manifestation of advanced atheromatous disease and is characterized by dense accumulation of extracellular lipid within the intima, known as a lipid core. At this stage in the disease, there is no fibrous tissue formation along the plaque nor are there surface defects or thrombosis. Macrophages, smooth muscle cells, and inflammatory cells (lymphocytes and mast cells) can be seen on the intimal border of the lipid core, whereas microvessels, macrophages, foam cells, and lymphocytes can be seen on the luminal surface of the plaque. ${ }^{45}$ Type IV lesions are considered clinically significant as the luminal surface of the plaque lacks a fibrous covering, leaving proteoglycans and foam cells at the luminal surface. The abundance of macrophages at the luminal surface renders the plaque prone to fissuring and rapid progression to a Type VI lesion, as described below. ${ }^{100}$

Type V lesions are characterized by development of a fibrous cap overlying the lipid core. Fibroatheroma (Type Va) is characterized by a lipid core with a fibrous cap, Type $\mathrm{Vb}$ is characterized by partial calcification of the lipid core and other parts of the plaque, and lipid-poor plaques are classified as Type Vc. It is at this stage that arterial narrowing occurs. Histologically, Type V lesions demonstrate increased capillary proliferation around the lipid core and the presence of lymphocytes, macrophages, plasma cells, and microhemorrhages. Inflammation is also seen in the vasa vasorum of the artery wall. ${ }^{100}$ These plaques are considered clinically relevant because they are prone to fissuring, hematoma development, and thrombus and thus progression to Type VI lesions.

Arterial ischemic stroke secondary to extracranial carotid artery disease is thought to be due to progression of Type IV and V plaques to Type VI plaques. Type VI plaques are characterized by fissuring of the luminal surface of the plaque, hemorrhage, and thrombotic deposits. Disruption of the plaque due to inflammatory and hemodynamic factors leads to ulceration and fissuring. ${ }^{34,103} \mathrm{Ul}$ ceration and fissuring of the plaque result in loss of the normal endothelium and luminal exposure of the necrotic lipid core. IPH also occurs due to disruption of some newly formed vasa vasorum proliferation within the plaque.? This process is extremely prothrombotic and puts the patient at risk for ischemic events. These fissured and ulcerated plaques can reseal around the thrombi and hemorrhage, resulting in intraplaque hematomas and intraplaque thrombus. ${ }^{29}$ As this process recurs, the plaque can rapidly expand, resulting in rapid progression of stenosis, as well as increased incidence of distal thromboembolic events. ${ }^{100}$ A summary of the histopathological grading of atheromatous plaques is provided in Table 1. 
TABLE 1. Summary of histopathological features of atheromatous plaques

\begin{tabular}{|c|c|c|}
\hline AHA Plaque Type & Histopathological Findings & Symptomatic Status \\
\hline Type I & Isolated deposition of macrophages \& foam cells. & Asymptomatic \\
\hline Type II & Fatty streak lesion w/ mainly intracellular lipid accumulation. & Asymptomatic \\
\hline Type III & Deposition of intracellular lipids w/in the plaque. & Asymptomatic \\
\hline Type IV & $\begin{array}{l}\text { Dense accumulation of extracellular lipid (i.e., lipid core). Inflammatory cell infiltration. No fibrous tissue } \\
\text { formation, no surface defects or thrombosis. }\end{array}$ & Possibly symptomatic \\
\hline Type V & $\begin{array}{l}\text { Fibrous cap overlying necrotic lipid core. Inflammation w/in plaque \& in the vasa vasorum of the artery wall. } \\
\text { Prone to hematoma, thrombus formation, \& fissuring. }\end{array}$ & Possibly symptomatic \\
\hline Type VI & $\begin{array}{l}\text { Fissuring \& ulceration of plaque. Necrotic lipid core. Intraplaque hemorrhage \& thrombus. Inflammation } \\
\text { w/in the plaque. }\end{array}$ & Probably symptomatic \\
\hline
\end{tabular}

The above findings are well validated in histopathological studies of carotid plaques. Histopathological studies of symptomatic plaques have demonstrated high concentrations of inflammatory cells, such as macrophages and lymphocytes, with associated focal areas of loss of the fibrous cap. ${ }^{14}$ Symptomatic carotid plaques have also been demonstrated to have higher rates of IPH and increased presence of lipid-rich necrotic cores (LRNCs), neovascularization, thin fibrous plaque, and plaque thrombus on histological studies. ${ }^{52,62,63}$ In contrast, stable carotid plaques are characterized by a thick fibrotic cap without a lipid-rich core. The goal of plaque imaging is to distinguish plaques based on these features. ${ }^{67}$

\section{Magnetic Resonance Imaging Imaging Techniques}

MRI is the most well-established imaging modality for plaque characterization. There is a wide variety of pulse sequences available for plaque characterization with MRI. Fast spin echo (FSE) is a commonly used technique, which allows for T1-, T2-, and proton density-weighted (PDW) imaging. FSE sequences allow for an extremely high spatial resolution and signal-to-noise ratio, especially with the use of a surface or phased-array coil, but suffer from prolonged scanning times, leading to potentially higher rates of motion artifact. However, many techniques are available to reduce scan time. ${ }^{35,39}$ Gradient echo imaging with or without an inversion recovery preparatory pulse is another technique that allows for rapid image acquisition and can be used with high reliability to detect IPH and LRNC on T1-weighted images. ${ }^{12}$

Another popular technique for plaque imaging is the black-blood technique. This method uses an FSE sequence with double inversion recovery preparatory pulses, which results in high contrast between the dark lumen and the vessel wall. The high signal-to-noise ratio comes at the cost of long examination times. However, techniques are being developed to decrease image acquisition time while preserving the high signal-to-noise ratio provided by the black-blood technique, to allow for a simple and quick assessment of IPH on T1-weighted images. ${ }^{82}$

Fat suppression is essential for proper characterization of plaque morphology. This method is used in all sequences to suppress the signal of subcutaneous fat, thus resulting in improved contrast between various plaque components as well as between the carotid wall and surrounding tissues. Furthermore, fat-suppressed T1-weighted images are helpful in distinguishing between the high T1 signal of intraplaque lipid and that of IPH. ${ }^{117}$

Contrast-enhanced images are essential in differentiating between various plaque components. Gadolinium (Gd)-based contrast imaging can be used to evaluate plaque neovascularity, as well as differentiate necrotic core from fibrous tissue on T1-weighted images. The LRNC and IPH do not enhance since these components are avascular, whereas the fibrous cap component of the plaque does. Increased enhancement with Gd is also associated with neovascularity and plaque inflammation. ${ }^{33,123}$ Ultrasmall superparamagnetic iron oxide (USPIO) particles are another contrast agent used in plaque evaluation. These particles result in magnetic susceptibility on $\mathrm{T} 2$ *- $^{-}$ weighted images. ${ }^{15,117}$

\section{Characteristics of Unstable Plaques on MRI}

Studies comparing MRI findings with histopathology have demonstrated that MRI can accurately distinguish between plaque calcification (Fig. 1), fibrous cap, IPH (Fig. 2), and LRNC (Fig. 3). ${ }^{22}$ MRI is excellent at detecting and differentiating between LRNC and IPH. IPH is often diffusely located within the plaque and located in the LRNC. Given the high T1 signal of the lipid-rich core and IPH, several studies have devised techniques to distinguish between the two. Multisequence protocols are essential to differentiate these 2 entities. ${ }^{22}$ When combining T1-weighted with time of flight (TOF) MR images, IPH is often hyperintense on both sequences, whereas LRNC is hyperintense only on T1-weighted and isointense on TOF MR images. ${ }^{22,127}$ The addition of T2-weighted and PDW sequences helps to further identify IPH. Fresh IPH is hyperintense on T1 and hypointense/isointense on T2 and PDW images. Recent IPH (1-6 weeks) is hyperintense on all contrast weightings, and old ( $>6$ weeks) IPH is hypointense on all contrast weightings. ${ }^{17,22}$ Fat-saturated black-blood FSE images can be used to saturate the fat in the LRNC to help further identify hemorrhage. The correlation between MRI and histopathological findings of LRNC and IPH is extremely strong. Sensitivity and specificity for detection of these 2 entities are very strong, and interobserver agreement for their detection and differentiation is excellent. ${ }^{13,22}$

Plaque enhancement on postcontrast T1-weighted MR 
Calcified plaque
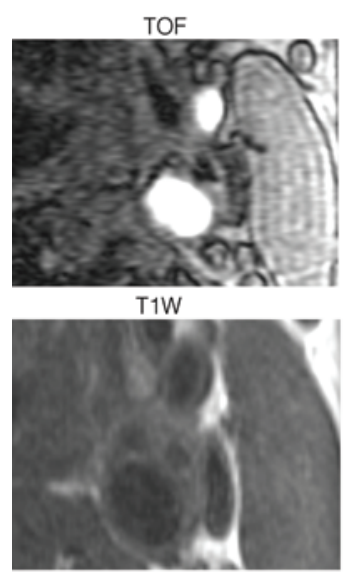

PDW

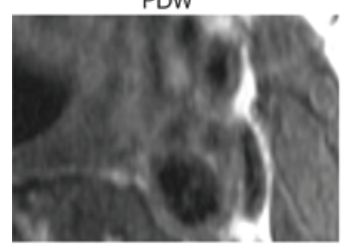

T2W

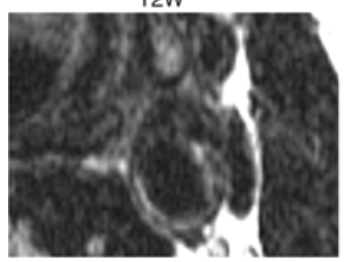

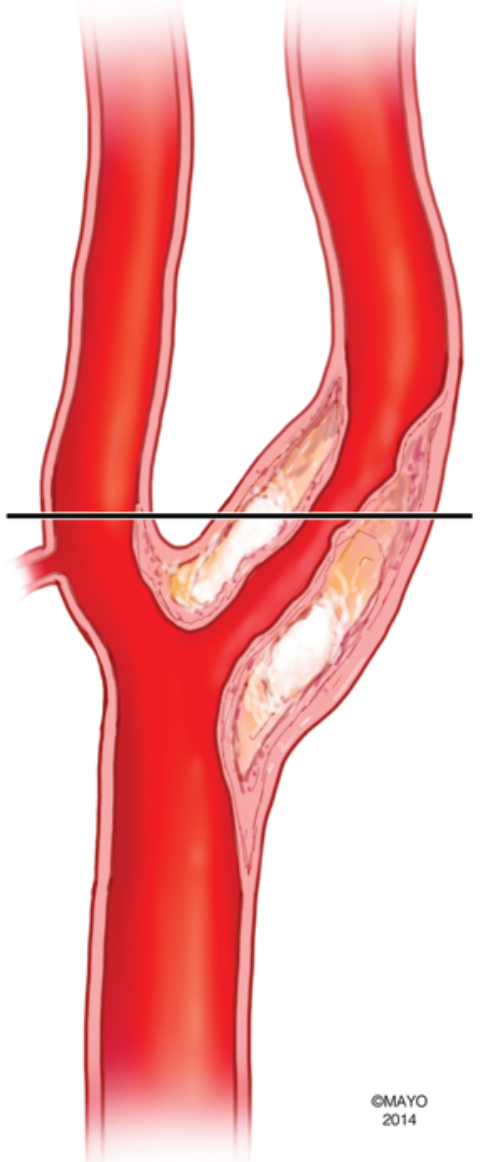

FIG. 1. Cross-sectional images of a calcified internal carotid artery (ICA) plaque. Areas of low signal can be seen on TOF, T1-weighted (T1W), PDW, and T2-weighted (T2W) images. These correspond to areas of calcification within the plaque. Copyright Mayo Clinic. Published with permission.

images is associated with plaque vulnerability, neovascularization, and macrophage infiltration. Prior studies have used dynamic contrast-enhanced (DCE) MRI to quantify plaque enhancement and thus neovascularity and inflammation. Adventitial $\mathrm{K}^{\text {trans }}$ (volume transfer coefficient) as calculated by DCE MRI has a strong correlation with plaque neovascularity and inflammation. ${ }^{49}$ This technique has been shown to be highly reproducible and reliable. ${ }^{33}$ Millon et al. demonstrated that neovascularity is seen in up to $97 \%$ of areas with Gd enhancement on postcontrast images, whereas macrophage infiltration is seen in $87 \%$ of regions of Gd enhancement. ${ }^{64} \mathrm{~T} 2 *$ susceptibility with USPIO contrast agents have been shown to be strongly associated with carotid plaque inflammation and macrophage infiltration on histopathological studies as these particles are taken up by macrophages. ${ }^{15,117}$

MRI is extremely sensitive in detecting plaque ulceration (Fig. 4). In MR angiography (MRA), the fibrous cap appears as a dark band between the bright lumen and the gray plaque. The absence of the thin, dark band signals plaque ulceration. The best technique for detec-
Hemorrhagic plaque

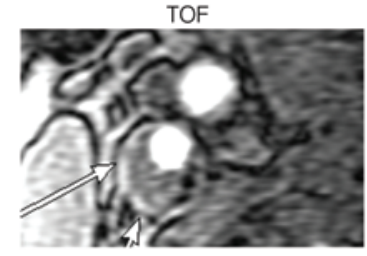

T1W
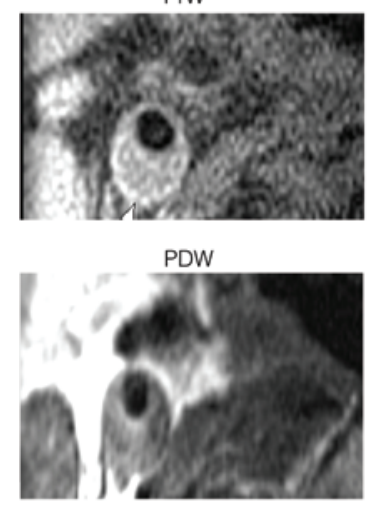

T2W

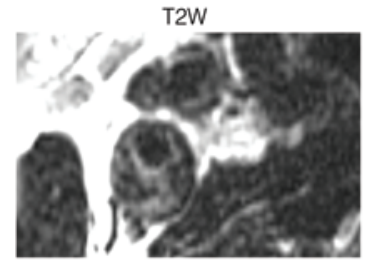

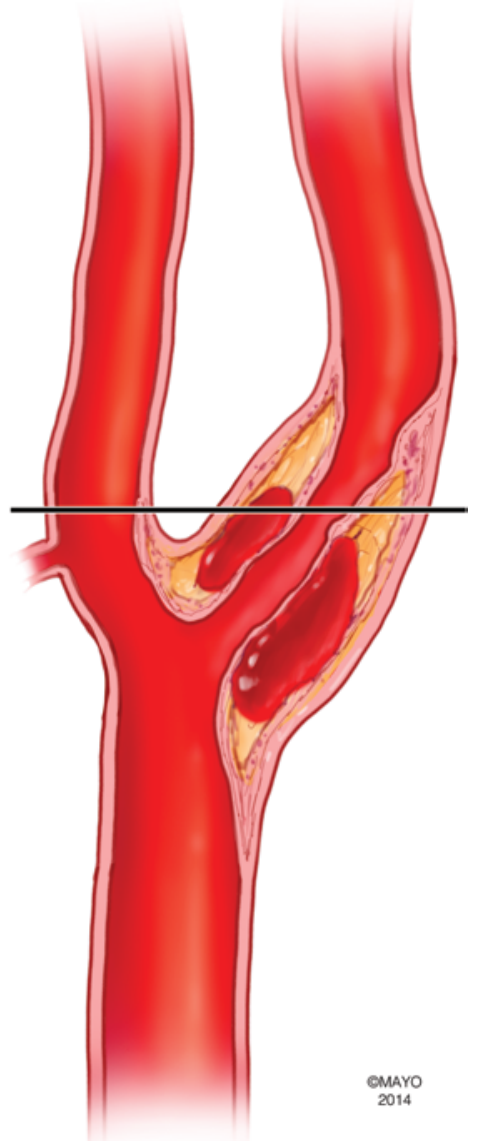

FIG. 2. Cross-sectional images of a hemorrhagic ICA plaque. TOF, T1-weighted (T1W), PDW, and T2-weighted (T2W) images show areas of high signal within the carotid plaque. PDW and T2-weighted images demonstrate some areas of heterogeneously low signal as well. These findings are most consistent with a hemorrhagic component of the plaque. Copyright Mayo Clinic. Published with permission.

tion of plaque ulceration is contrast-enhanced MRA. ${ }^{26} \mathrm{In}$ terobserver agreement for detection of plaque ulceration is good, with kappa values ranging from 0.74 to $0.85 .^{22}$ Plaque calcification is detected by MRI with both high sensitivity and specificity. ${ }^{22,81}$ Calcifications are usually hypointense on all contrast-weighted sequences.

Plaque characterization with MRI has been shown to be a valuable tool in predicting subsequent ischemic events. In a systematic review of 9 studies involving 779 subjects, Gupta et al. found that IPH, LRNC, and thinning/rupture of the fibrous cap were associated with hazard ratios of 4.59, 3.00, and 5.93, respectively, for subsequent TIA or stroke. ${ }^{36}$ In fact, MRI plaque characteristics have been found to have a stronger association with patient symptomatic status than degree of stenosis. One large crosssectional study of 97 patients with 50\%-99\% stenosis found that the presence of a LRNC and thin or ruptured fibrous cap was associated with symptomatic events, whereas the degree of stenosis was not. The size of LRNC and presence of ulceration have been found to be independent predictors of symptomatic events in one study. ${ }^{17}$ 
Lipid Rich Necrotic Core

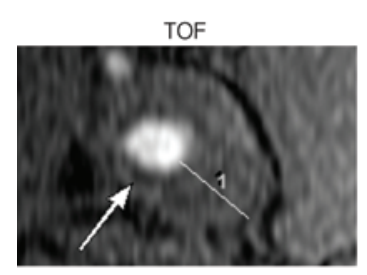

T1W

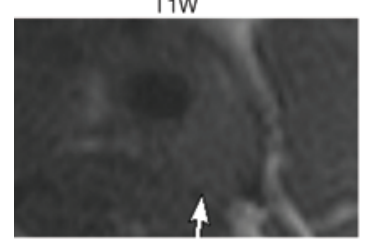

PDW

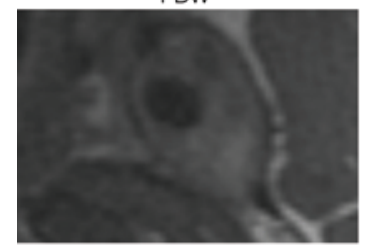

T2W

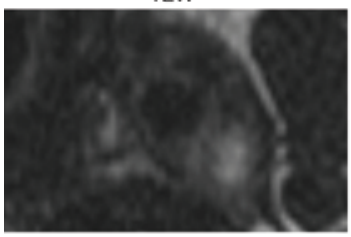

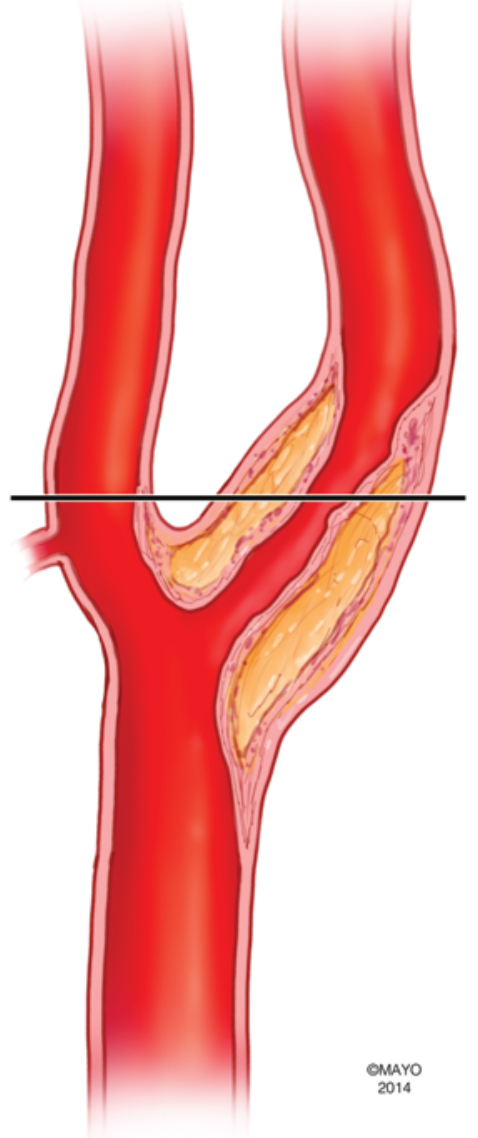

FIG. 3. Cross-sectional images of an LRNC. PDW and T2-weighted (T2W) images showing hyperintensity. T1-weighted (T1W) image showing heterogeneous, isointense signal of the plaque. Copyright Mayo Clinic. Published with permission.

IPH has also been found to have a very strong association with symptomatic events independent of degree of stenosis. Studies of both asymptomatic and symptomatic patients with moderate $(<70 \%)$ carotid stenosis have found that MRI findings of IPH are associated with a higher hazard ratio of future ipsilateral ischemic events. ${ }^{3,96}$ One meta-analysis of 8 studies found that IPH was associated with stroke at a rate of $17.7 \%$ per year of follow-up..$^{83}$

Plaque enhancement, a marker of plaque neovascularization and inflammation, is also strongly associated with symptomatic events. Prior studies have demonstrated that plaque enhancement on DCE MRI is significantly associated with ipsilateral ischemic events, independent of degree of stenosis. ${ }^{64,74}$ These studies are in accord with previous reports demonstrating the increased expression of the angiogenic pathway in unstable plaques, thus underscoring the seminal role of plaque neovascularization in plaque vulnerability. A summary of imaging characteristics of vulnerable plaques on MRI is provided in Table 2.

\section{Medical and Surgical Therapy}

In vivo MRI has been used to evaluate the efficacy of pharmacological therapy in improving plaque stability. In

\section{Ruptured plaque}

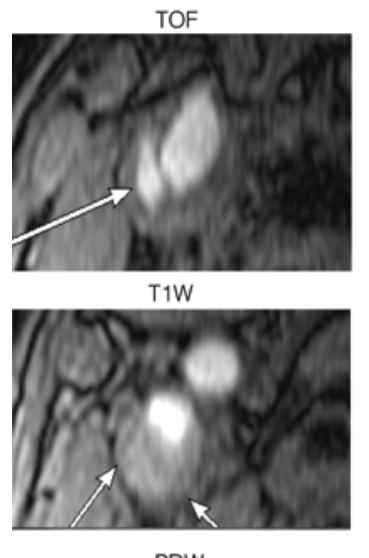

PDW
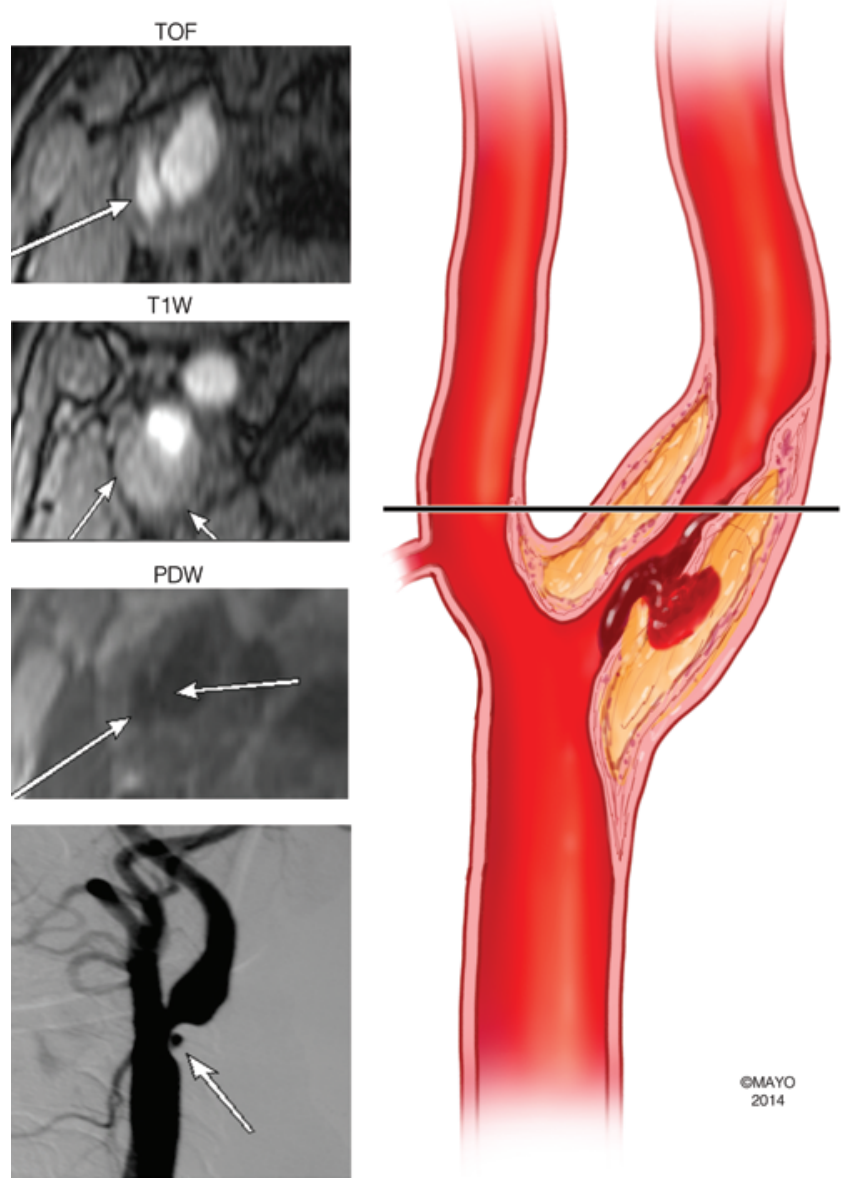

FIG. 4. Images of an ICA plaque rupture with hemorrhagic component. TOF and PDW images demonstrate the site of the plaque rupture with irregularity of the carotid artery lumen (arrows). T1-weighted image (T1W) showing hyperintense signal within the carotid plaque consistent with hemorrhage as well as some luminal irregularity. Conventional angiogram demonstrates a focal ulceration within the plaque (arrow in bottom image). Copyright Mayo Clinic. Published with permission.

fact, one randomized trial comparing efficacy of statin versus niacin plus statin used MRI to characterize carotid plaque regression and found that both treatment regimens resulted in similar, but significant, reductions in plaque volume..$^{93}$ Another trial used MR plaque imaging to demonstrate that intensive lipid therapy with atorvastatin resulted in significant reductions in the carotid plaque LRNC volume. ${ }^{128}$ Serial MRI studies have also demonstrated that high-dose rosuvastatin is associated with marked $(60 \%)$ reduction in LRNC volume. ${ }^{12}$

MR plaque imaging has also been used to identify surgical candidates. Yoshida et al. found that patients with low-grade carotid stenosis with IPH on MRI had high rates of ischemic events even when placed on antithrombotics and statins. Because these patients with IPH were refractory to medical therapy, they elected to proceed with endarterectomy and found that surgery was associated with marked reductions in subsequent ischemic events. ${ }^{124}$ MR plaque imaging has also been found to be useful in identifying revascularization candidates that would be 


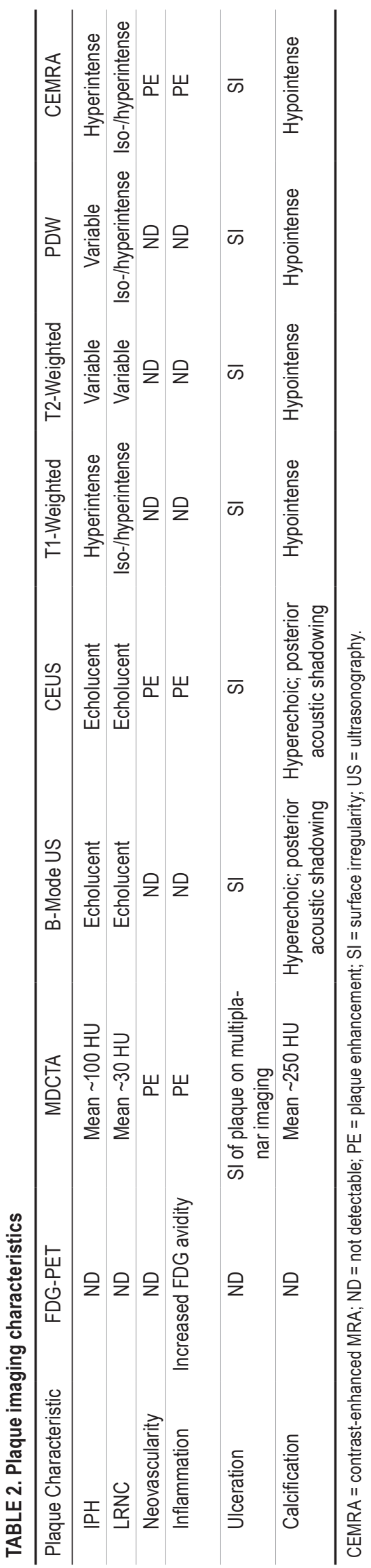

better candidates for carotid endarterectomy (CEA) than carotid artery stenting (CAS), as high intraplaque signal on TOF imaging has been shown to be associated with vulnerable plaque and increased rates of adverse events in patients undergoing CAS but not CEA. ${ }^{125,126}$

\section{Computed Tomography Imaging Techniques}

The 2 principal CT techniques for plaque characterization are multidetector-row CT (MDCT) and dual-source CT (DSCT). MDCT allows for multiplanar reconstructions in the axial, sagittal, and coronal planes, as well as high spatial and contrast resolution. Similar to MRI, CT allows for high, submillimeter spatial resolution. ${ }^{87}$ Plaques are imaged using a bolus tracking CT angiography (CTA) technique. Plaque calcification, fibrous plaque thickness, IPH, and LRNCs can be characterized on MDCT based on voxel Hounsfield units (HUs). ${ }^{1}$ The high resolution of MDCT allows for accurate identification of plaque ulcerations as small as $1 \mathrm{~mm}$ (Fig. 5). ${ }^{27,89}$ Plaque enhancement following contrast injection is also an extremely valuable imaging parameter ${ }^{87}$ The main limitations to MDCT include beam hardening artifact from densely calcified plaques, need for iodinated contrast, and radiation exposure.

DSCT uses 2 different $x$-ray sources at 2 different $x$ ray energies to achieve different HUs in the same tissue. This allows for better tissue differentiation and advanced postprocessing techniques. ${ }^{55}$ DSCT also has high spatial and temporal resolution and can be combined with boneremoval algorithms, thus offering better visualization of vasculature, with high spatial resolution and the capability to perform multiplanar reformats. ${ }^{20}$ Advantages of DSCT compared with standard MDCT include the ability to differentiate calcified plaque from iodinated contrast, thus allowing for accurate assessment of calcified plaque volume and easy bone subtraction. No studies to date have been performed comparing the sensitivity and specificity of DSCT and MDCT for plaque characterization. ${ }^{20}$

\section{Characteristics of Unstable Plaques on CT}

Prior studies characterizing components of unstable plaques have demonstrated that CT Hounsfield density can be used to distinguish between LRNC, connective tissue, IPH, and calcifications. Calcifications are easily identified by their high density (mean approximately $250 \mathrm{HU}$ ). However, there is considerable overlap between the $\mathrm{CT}$ densities of LRNC, connective tissue, and IPH (approximate means $30,45$, and $100 \mathrm{HU})$. For this reason, reliability is reduced when assessing plaque components on a pixel-by-pixel basis. However, macroscopic changes, such as large hemorrhage and large low-density lipid cores, can be easily recognized on MDCT with high interobserver agreement. ${ }^{1,121}$ As a general rule, the lower the density of the plaque, the more likely it is to be vulnerable. Examples of low-density vulnerable plaques are provided in Figs. 6 and 7.

MDCT is also very effective at detecting plaque ulcerations and plaque neovascularity, with sensitivities and specificities well over 90\%, especially with multiplanar imaging. ${ }^{84,85}$ Interobserver agreement for detection of 

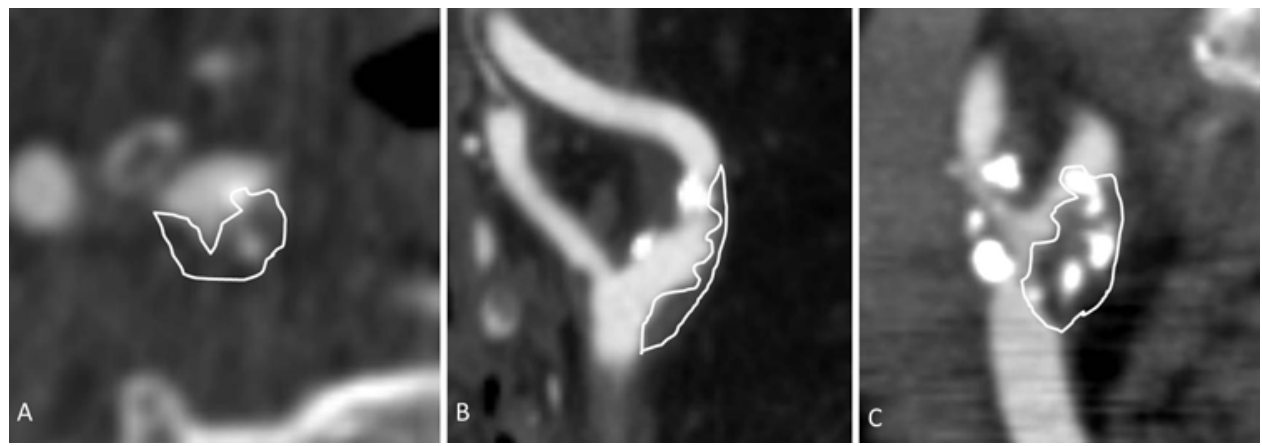

FIG. 5. MDCTA scans obtained in 3 separate patients with ulcerated plaques. A: Plaque found in a 53-year-old symptomatic male, resulting in a $50 \%$ stenosis. The surface is markedly ulcerated and demonstrates multiple areas of decreased density suggestive of LRNC. B: Plaque found in a symptomatic 64 -year-old female with a $40 \%$ stenosis. Ulcerations are shown along the plaque surface. C: Plaque found in a 75 -year-old male showing multiple areas of decreased density, as well as surface irregularity. The plaque resulted in a high-grade stenosis and was symptomatic. The white borders indicate the surface of the plaque.

plaque ulcerations and plaque enhancement is very high. Plaque contrast enhancement has been shown to be strongly associated with both plaque ulceration and neovascularity. ${ }^{86,89}$ However, sensitivity and specificity of blood-pool contrast-enhanced MRA exceeds that of MDCT angiography (MDCTA). ${ }^{4}$

MDCTA findings are strongly correlated with patient symptomatology as well. In a study of 97 patients, Saba and Mallarini found that symptomatic plaques had a significantly higher degree of plaque enhancement following contrast administration than asymptomatic plaques; a threshold of $15 \mathrm{HU}$ had a specificity of $83 \%$ and a sensitivity of $76 \% .{ }^{87}$ Delayed phase images have also been demonstrated to have a strong correlation with symptomatology, as patients with stable plaques have progressive enhancement of the plaque on delayed images while symptomatic plaques tend to have more washout. This is likely related to the presence of neovascularization within unstable plaques leading to increase washout of contrast on delayed images. ${ }^{42}$ Other MDCTA findings associated with symptomatology include a fissured fibrous cap and LRNC. ${ }^{88,120}$ A summary of CT characteristics of stable and vulnerable plaques is provided in Table 2 .

\section{CT Plaque Imaging in Medical Management}

Few studies have investigated the utility of MDCTA for monitoring response to medical therapy. In a study of 109 patients with history of TIA or ischemic stroke, van Gils et al. ${ }^{113}$ performed serial MDCTA of the carotid arteries over 5 years. This study demonstrated that MDCTA is a reliable method for monitoring plaque progression and response to therapy, with high rates of intraobserver and interobserver agreement. Furthermore, this study demonstrated that approximately one-third of patients who were on statin therapy following stroke had decreased plaque volume over time. ${ }^{113}$ No studies to date have used MDCTA plaque imaging to select candidates for revascularization therapy.

\section{Ultrasonography and Carotid Plaque Imaging} Imaging Techniques

B-mode ultrasonography and contrast-enhanced ultrasonography (CEUS) are the 2 most widely used techniques in evaluation of carotid plaque. B-mode examination is typically performed with a 4- to 7-MHz linear array transducer. Images are typically obtained in longitudinal section to maximize visualization of the atherosclerotic plaque. Color and power Doppler can be used to further delineate the plaque border. B-mode ultrasound images are used primarily in assessing the echogenicity of plaques. One of the limitations of B-mode characterization of carotid plaques is the lack of consistent inter- and intraobserver agreement, as well as poor signal-to-noise ratio. ${ }^{5}$ By applying a technique called real-time compounding, in which scan information from multiple angles is combined,
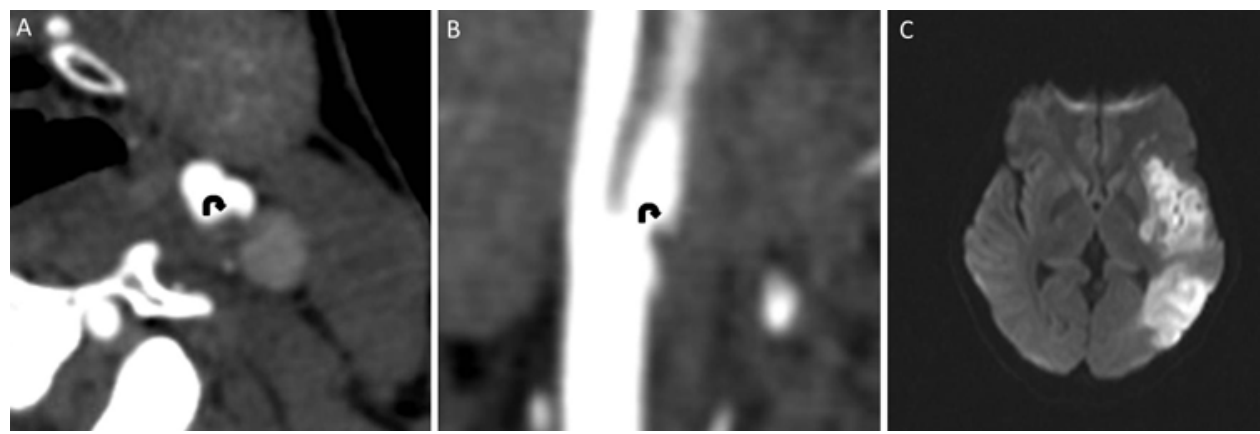

FIG. 6. Case of a 25-year-old female with sudden-onset, right-sided hemiparesis. A and B: High-resolution CTA of the left ICA showing a low-grade stenosis with a low-density plaque at the carotid bifurcation (curved arrows). Findings are suggestive of a vulnerable plaque. C: Diffusion-weighted axial MR image showing a large left middle cerebral artery territory infarction. 

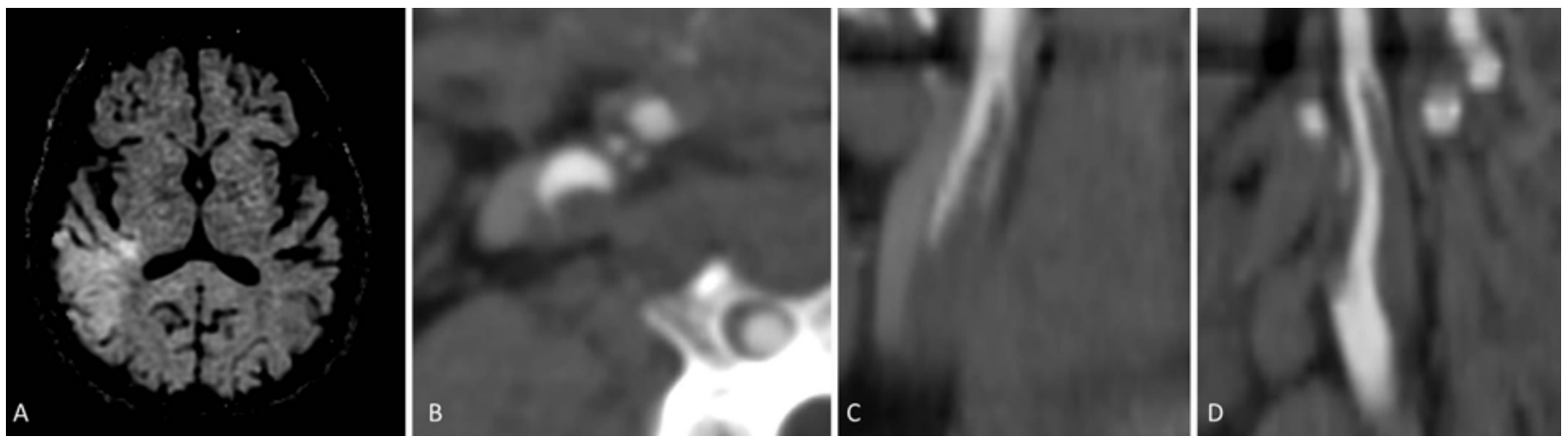

FIG. 7. Case of a 38-year-old male with sudden-onset, left-sided weakness. A: Axial MR image showing restricted diffusion in the right temporoparietal lobe. B: CT angiogram of the right carotid bifurcation showing a low-density plaque $(47 \mathrm{HU})$ in the right carotid bifurcation. C and D: Part of the plaque is not adhered to the wall and is floating in the lumen of the ICA. The plaque is resulting in an approximately $60 \%$ luminal stenosis. This is an example of a vulnerable plaque on CTA.

signal-to-noise ratio and interobserver agreement can be improved. ${ }^{48,119}$ In addition, image processing techniques should be applied to best assess plaque echogenicity. ${ }^{54}$ However, many studies use the echogenicity of the overlying sternocleidomastoid muscle as a reference for plaque echogenicity. Operator variability is also a major limitation to B-mode plaque characterization.

Most recent developments in carotid plaque characterization with ultrasound have come in the field of CEUS. ${ }^{108}$ CEUS uses an intravenous microbubble contrast agent. These bubbles do not diffuse into surrounding tissues like other contrast agents; consequently, all signals from CEUS examinations are intravascular, which allows for accurate assessment of vessel lumen and neovascularity within the carotid plaque. In the setting of carotid stenosis, CEUS can be used to distinguish between total carotid occlusion and high-grade stenosis, identify plaque ulceration, and evaluate carotid plaque neovascularization. ${ }^{25,30,73}$ Specific, commercially available pulse sequences are needed to suppress signal from tissue within the image and accentuate signal from the intravascular bubbles. Quantitative methods have been established to improve reproducibility of measurements of contrast enhancement. ${ }^{108}$ There are, however, limitations to use of CEUS. Contraindications to microbubbles include allergy, acute heart failure, endocarditis, right to left shunts, and unstable angina. ${ }^{108}$ This technique is highly operator dependent and prone to high interobserver variability. ${ }^{44}$ Also, CEUS is prone to an artifact known as pseudoenhancement, in which ultrasound waves are propagated through the contrast agent leading to increased signal in the vessel wall furthest from the probe, thus leading to overinterpretation of vessel wall enhancement. ${ }^{107}$

\section{Plaque Characterization With B-Mode and CEUS B-Mode}

A strong correlation has been demonstrated between sonographic and histopathological features of carotid plaques using B-mode ultrasound. ${ }^{76} \mathrm{~B}$-mode carotid ultrasonography has high specificity but only moderate sensitivity in identifying ulceration of the plaque surface. $\mathrm{Ab}$ sent, thin, or ruptured echogenic caps are established risk factors for acute ischemic stroke. Large plaque ulcerations are easily identified as obvious craters within the plaque, with reversed or stagnated flow (Fig. 8). There is wide variability in the prevalence of ulceration in symptomatic plaques on B-mode ultrasonography ranging from $5 \%$ to 40\%. $25,38,70$ Ultrasonography lacks sensitivity for the detection of plaque ulceration compared with CT, MRI, and histopathological studies. ${ }^{18}$ Sensitivity is especially poor in examining patients with moderate stenosis,${ }^{84}$ in whom determining the presence of ulceration is important due to the potential for changing the therapeutic approach. ${ }^{6}$ Some authors have suggested that this poor sensitivity can be improved by changing the diagnostic criteria for plaque ulceration. ${ }^{69}$ Conventional criteria require the size of the concavity to be greater than $2 \times 2 \mathrm{~mm}$ and the presence of a color Doppler flow signal within the concavity. However, Muraki et al. argue that considering any concavity with an echogenic line at the plaque base as diagnostic of plaque ulceration is significantly more sensitive and specific. ${ }^{69}$

Plaque echolucency is another strong marker of plaque vulnerability (Figs. 9 and 10). This is the sonographic equivalent of a LRNC. Plaque echolucency is seen in up to $50 \%$ of recently symptomatic plaques compared with less than 5\% of asymptomatic plaques., ${ }^{2,60,95}$ Furthermore, the risk of stroke among patients with echolucent plaques, regardless of degree of stenosis, is up to $13 \%$, which is higher than the risk of stroke among patients with highgrade stenosis..$^{60}$ In addition, the size of the juxtaluminal hypoechoic area of the carotid plaque is strongly associated with stroke risk.

\section{CEUS}

CEUS is used primarily to identify neovascularization within carotid plaques. Histological examinations have demonstrated that plaque enhancement is strongly associated with plaque neovascularity and inflammation. ${ }^{19,115} \mathrm{~A}$ number of inflammatory markers including matrix metalloproteinase-9 (MMP-9) are highly expressed in enhancing plaques..$^{50,91}$ Studies comparing plaque enhancement in asymptomatic and symptomatic plaques have demonstrated that plaque enhancement is markedly increased in patients with symptomatic plaque and is associated with a higher rate of cardiovascular events in general. ${ }^{102,122,130}$ Retention of microbubbles on the plaque surface on delayed images has been shown to correlate with plaque disruption and inflammation as macrophages are known to 

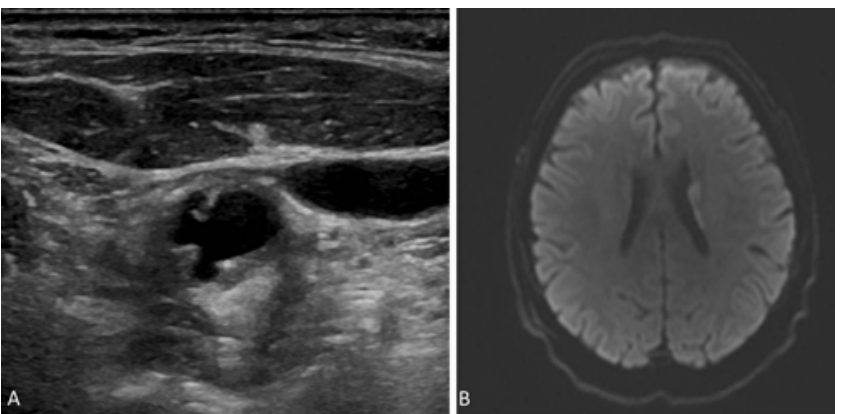

FIG. 8. Case of a 72-year-old male who presented with aphasia and right-sided weakness. A: Ultrasonography of the left ICA showing an ulcerated plaque at the carotid bifurcation but no significant stenosis. B: Diffusion-weighted axial MR image showing a focal infarct in the left caudate. This case demonstrates nicely how an ulcerated plaque in the absence of a significant stenosis can produce a symptomatic event.

phagocytose this contrast agent. ${ }^{56}$ When combined with B-mode ultrasonography, CEUS provides further details in plaque characterization. More than $90 \%$ of echolucent plaques demonstrate contrast enhancement. ${ }^{18,43}$ Contrast bubble agents are also used in characterizing the plaque surface. Disruptions in the plaque-lumen border are easily characterized using CEUS. Compared with B-mode and color-Doppler ultrasonography, CEUS has higher interobserver agreement, sensitivity, specificity, and accuracy in identifying plaque ulceration. ${ }^{109} \mathrm{~A}$ summary of plaque characteristics on ultrasonography evaluation is provided in Table 1.

\section{Ultrasound Plaque Imaging in Medical and Surgical Management}

Carotid ultrasonography is emerging as an effective tool to monitor response to lipid-lowering therapy. One study found that $80 \mathrm{mg} /$ day of atorvastatin resulted in decreased echolucency of carotid artery plaques within just 30 days of treatment. ${ }^{21}$ Others have found that patients with moderate carotid stenosis on an aggressive atorvastatin regimen demonstrate increased plaque echogenicity after 12 months of treatment. ${ }^{47}$ Plaque neovascularization on CEUS is also known to decrease following statin therapy. These findings highlight the role that detailed carotid ultrasonography can play in monitoring response to therapy. ${ }^{23}$

Plaque imaging on ultrasonography has also been effectively used in selecting carotid revascularization candidates. Ballotta et al. ${ }^{6}$ used CEUS to select patients with symptomatic carotid plaques with $<50 \%$ stenosis. In this study, the authors selected patients with enhancing and echolucent or heterogeneous plaques with surface irregularities, ulcer, or rupture for surgical treatment and found stroke-free survival rates of $98 \%$ at 1 year using these criteria. ${ }^{6}$ Further studies are needed to determine whether plaque characteristics on CEUS and B-mode ultrasonography can be reliably used to select surgical candidates with low-grade stenosis.

\section{Transcranial Doppler Ultrasonography}

\section{Techniques}

Transcranial Doppler ultrasonography (TCD) is a por-
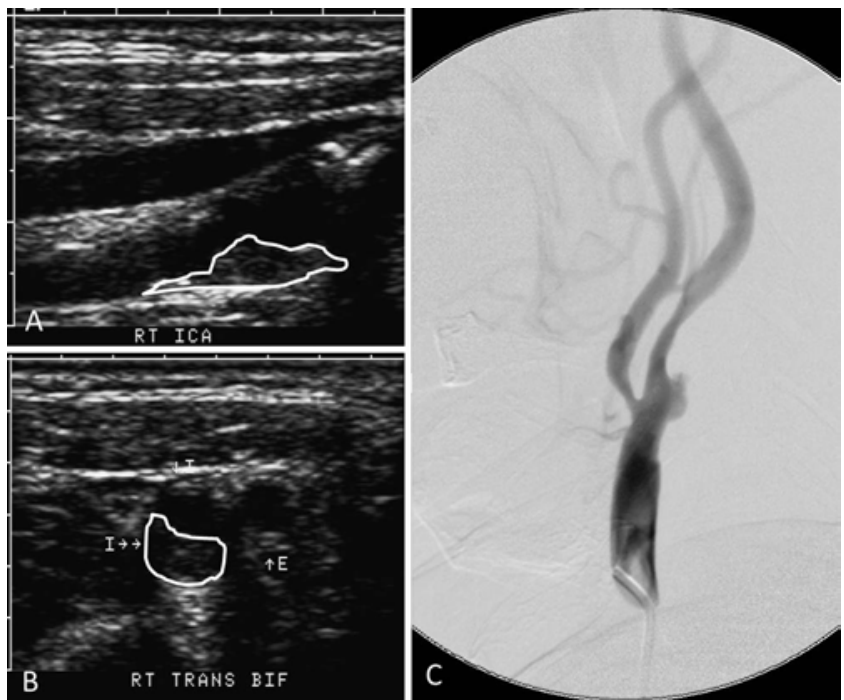

FIG. 9. Case of a 64-year-old male with ipsilateral stroke. A and B: Carotid ultrasonography showing a hypoechoic and ulcerated plaque of the right ICA (outlined with white border). Degree of stenosis was $<70 \%$ on ultrasonography. C: Follow-up digital subtraction angiography showing a markedly irregular and ulcerated plaque involving the right carotid bulb and a long segment of $55 \%$ ICA stenosis.

table and noninvasive technique used to image the intracranial vasculature. Generally, imaging is performed with a low-frequency $(2 \mathrm{MHz})$ sector-array transducer to allow penetration of signal through the calvaria. Transtemporal, transforaminal, and transorbital acoustic windows can be used for imaging. ${ }^{51}$ One potential side effect of TCD is thermal injury, especially when using the transorbital window, but this is only a concern when higher frequencies are employed.

The principle role of TCD in carotid imaging is the evaluation of cerebral microembolic signals (MESs). ${ }^{57,98}$ The middle cerebral artery is the preferred artery to monitor. A number of studies have suggested that MESs detected in patients with carotid artery disease are due to unstable plaque. This is further supported by the fact that MESs rapidly diminish following CEA. ${ }^{114}$

\section{Role in Risk Stratification}

MESs are a strong marker of unstable plaque. In a systematic review of the literature, Ritter et al. ${ }^{77}$ found that $43 \%$ of patients with symptomatic carotid stenosis had MESs on TCD compared with just $10 \%$ of asymptomatic patients. Furthermore, presence of just 1 MES was associated with 7.5 times higher odds of future symptomatic event in symptomatic patients and 13.4 times higher odds of embolic event in asymptomatic patients. ${ }^{77}$ Conversely, absence of MESs is associated with a very low risk of future symptoms in patients with asymptomatic carotid plaques..$^{97} \mathrm{TCD}$ is especially helpful when combined with other imaging modalities. Topakian et al. found that the combination of plaque echolucency on B-mode ultrasonography and MESs on TCD was associated with a 10 times higher risk of stroke in patients with asymptomatic carotid stenosis. These patients had an annual stroke risk of $8 \%$ compared with $<1 \%$ in the low-risk cohort. ${ }^{110}$ The 

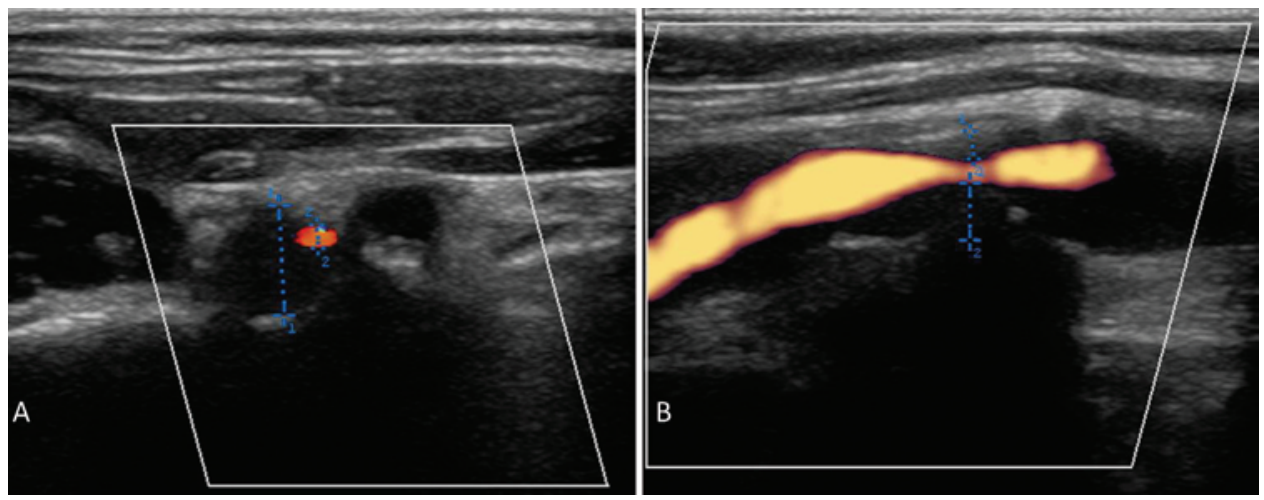

FIG. 10. Ultrasonography of the right ICA in transverse (A) and longitudinal (B) planes showing a high-grade stenosis and markedly hypoechoic plaque. The plaque demonstrates markedly decreased echogenicity compared with the overlying sternocleidomastoid muscle. Figure is available in color online only.

combination of plaque neovascularization on CEUS and MESs on TCD is also emerging as a strong risk factor for acute ischemic stroke. ${ }^{78,129}$

\section{Molecular Imaging \\ Techniques}

The main molecular imaging technique used to evaluate carotid plaques is ${ }^{18} \mathrm{~F}$-fluorodeoxyglucose (FDG) PET/ CT. FDG is partially metabolized through glycolysis within the atherosclerotic plaque and serves as a marker of plaque inflammation and hypoxia. ${ }^{31}$ FDG is injected intravenously, and image acquisition is performed after 60-180 minutes. Imaging is typically performed on a dedicated PET/CT scanner, and images are reconstructed into coronal, transverse, and sagittal planes. Corrections are applied for attenuation, scatter, random coincidences, and scanner dead time. Low-dose CT imaging is typically performed for both anatomical localization and attenuation correction. ${ }^{92}$

There are a number of variables that need special attention when characterizing plaques with FDG-PET/CT. First, following injection of FDG, the concentration of FDG in the blood pool can result in poor contrast resolution when evaluating a small area such as a carotid plaque. For this reason, there is much debate regarding the ideal timing for imaging following FDG administration. Typically, when performing imaging for malignancy staging, images are obtained 1 hour following intravenous administration of FDG. However, imaging this early may result in low contrast resolution. Over time, blood activity declines and contrast resolution improves. In a study of patients undergoing imaging for carotid plaques, Blomberg et al. ${ }^{10}$ found that imaging at 180 minutes resulted in improved quantitation of atherosclerotic plaque inflammation compared with imaging at 90 minutes, as target-to-background ratios (TBRs) were highest at this point. Furthermore, carotid maximal standardized uptake value (SUVmax) at 180 minutes was more strongly associated with 10 -year risk for fatal cardiovascular disease compared with imaging at 90 minutes..$^{10}$

Another important variable is carotid plaque metabolism. The 2 principle quantitative methods for evaluat- ing this variable are TBR and standardized uptake value (SUV). Furthermore, these values can be broken down into maximum and mean TBR and SUV values. Blomberg et al. suggested that the SUVmax of the carotid plaque is the most reliable surrogate for plaque vulnerability. ${ }^{10} \mathrm{How}-$ ever, Niccoli-Asabella et al. argued that TBR maximal and mean values are more reliable than SUV in identifying inflamed plaques. ${ }^{71}$ One advantage of FDG-PET imaging of carotid plaques is the high reproducibility of measurement techniques. Numerous studies have found that inter- and intraobserver agreement for plaque characterization is excellent (interclass correlation values greater than 0.90). ${ }^{79,80}$

\section{Plaque Characterization With Molecular Imaging}

A number of studies have been performed correlating findings from FDG-PET/CT and histopathological examination. Masteling et al. found that high FDG activity in carotid plaques was localized to areas with macrophage infiltration. ${ }^{59}$ In a study of 21 patients undergoing CEA following FDG-PET/CTA, SUVmax was associated with increased concentration of CD68, a marker of macrophage activity. ${ }^{61}$ In a small study, Tawakol et al. also found that CD68 staining was higher in high SUV plaques than in low SUV plaques. ${ }^{106}$ Other studies have correlated FDGPET findings with MR plaque imaging and have found that FDG uptake is higher in lipid-rich plaques compared with collagen-rich plaques. ${ }^{94}$ Although FDG uptake is strongly associated with inflammation, the relationship between FDG uptake and plaque neovascularization is considered weak at best. ${ }^{13}$ Thus, this imaging modality may not be the ideal choice to assess plaque vulnerability and progression.

Several studies have demonstrated that increased FDG uptake in carotid plaques is associated with clinical symptoms as FDG-avid plaques are significantly more likely to be found in symptomatic patients and are known to be associated with future ischemic events. ${ }^{53,58,66} \mathrm{FDG}$ imaging of carotid plaques shows the most promise when used as an adjunct to other imaging modalities, especially MRI. A number of investigators have examined the value of the combination of FDG-PET to detect active inflammation and MRI to identify worrisome morphological features for the optimization of risk stratification. In a study of 49 
TABLE 3. Advantages and disadvantages of imaging techniques

\begin{tabular}{|c|c|c|}
\hline $\begin{array}{l}\text { Imaging } \\
\text { Modality }\end{array}$ & Advantages & Disadvantages \\
\hline MRI & $\begin{array}{l}\text { Noninvasive; no radioactivity; high spatial \& contrast resolution; high sensitiv- } \\
\text { ity \& specificity for identifying IPH, plaque ulceration, LRNC, inflammation, } \\
\text { \& neovascularity; high reproducibility; high signal-to-noise ratio }\end{array}$ & Time constraints, cost, potential toxic effects of $\mathrm{Gd}$ \\
\hline CT & $\begin{array}{l}\text { Noninvasive; high spatial \& contrast resolution; high reproducibility; highly ac- } \\
\text { curate in detecting plaque calcification, ulceration, \& plaque enhancement/ } \\
\text { neovascularity }\end{array}$ & $\begin{array}{l}\text { Radiation; beam hardening artifact from dense calcification; } \\
\text { significant overlap in HU for IPH, LRNC, \& fibrous tissue; } \\
\text { intravenous contrast }\end{array}$ \\
\hline PET & Noninvasive, reproducible, highly accurate in identifying plaque inflammation & $\begin{array}{l}\text { Poor spatial resolution; radiation; time constraints; not able } \\
\text { to detect neovascularity, ulceration, LRNC, IPH }\end{array}$ \\
\hline US & $\begin{array}{l}\text { Noninvasive, no radioactivity, moderate spatial \& contrast resolution, accurate } \\
\text { in detecting large LRNC \& large plaque ulcerations }\end{array}$ & $\begin{array}{l}\text { Spatial \& contrast resolution not as good at CT \& MRI, poor } \\
\text { signal-to-noise ratio, operator dependent, more interob- } \\
\text { server variability than CT \& MRI, cannot differentiate IPH } \\
\text { \& LRNC }\end{array}$ \\
\hline CEUS & $\begin{array}{l}\text { Noninvasive, no radioactivity, moderate spatial \& contrast resolution, accurate } \\
\text { in detecting plaque neovascularity, superior to B-mode US in detecting } \\
\text { ulceration }\end{array}$ & $\begin{array}{l}\text { Spatial \& contrast resolution not as good at CT \& MRI, } \\
\text { operator dependent, more interobserver variability than } \\
\text { CT \& MRI, adverse effects of US contrast agent, US } \\
\text { contrast agent not yet approved in USA }\end{array}$ \\
\hline
\end{tabular}

patients, Truijman et al. found only a weak correlation between plaque inflammation on PET and neovascularization detected by DCE MRI. ${ }^{111}$ This suggests that these 2 techniques are complementary. Calcagno et al. found a weak inverse relationship between neovascularization on DCE MRI and plaque inflammation on PET.11 Similarly, FDG uptake did not strongly correlate with IPH seen on MRI. ${ }^{90}$ Further studies are needed to develop models that integrate findings from FDG-PET and MRI in risk stratification of carotid atherosclerotic disease. A summary of FDG-PET/CT characteristics of stable and vulnerable plaques is provided in Table 2. A summary of the advantages and disadvantages of carotid imaging techniques is provided in Table 3 .

\section{FDG-PET and Medical Therapy}

FDG-PET of carotid plaques has been used as a tool to monitor response to medical therapy in patients with carotid stenosis. In a study of 43 patients randomized to simvastatin versus no simvastatin, Tahara et al. found that statin therapy resulted in a significant reduction of SUVmax in carotid plaques. ${ }^{104}$ Tawakol et al. found that intensive statin therapy produced significant dose-dependent reductions in FDG uptake after just 4 weeks of therapy. ${ }^{105}$ Mizoguchi et al. found that pioglitazone attenuated FDG uptake and thus inflammation in diabetic patients with carotid atherosclerotic disease. ${ }^{65}$ Thus, FDG-PET is emerging as a promising tool to measure response to therapy in patients with carotid atherosclerosis. To date, no large studies have been performed using FDG-PET to identify candidates for carotid revascularization.

\section{Other Molecular Markers}

A number of other molecular markers have been applied to plaque imaging. ${ }^{18} \mathrm{~F}$-sodium fluoride $(\mathrm{NaF})$ is another tracer that targets active microcalcifications in atherosclerotic plaques. Microscopic deposits of calcium are thought to signal plaque progression, rupture, and inflam- mation. ${ }^{16}$ Joshi et al. found that ${ }^{18} \mathrm{~F}-\mathrm{NaF}$ PET/CT was more reliable than FDG-PET in identifying vulnerable coronary plaques. In carotid artery specimens, these authors found that ${ }^{18} \mathrm{~F}-\mathrm{NaF}$ uptake occurred at the site of all carotid plaque ruptures and was strongly associated with active calcification, macrophage infiltration, apoptosis, and necrosis. ${ }^{46}$ A number of imaging agents targeting molecules that are highly expressed within vulnerable plaques have been proposed as well. For example, ${ }^{18} \mathrm{~F}$-galacto-RGD has been shown to target $\alpha v \beta 3$, an integrin highly expressed in angiogenic cells and macrophages. ${ }^{9}{ }^{18} \mathrm{~F}$-folate has been shown to target folate receptors highly expressed in macrophages. ${ }^{68}$ Imaging of matrix metalloproteinases, proteases associated with plaque rupture, has also shown promise in early preclinical studies. ${ }^{40}$ None of these radiotracers have been validated in large clinical studies as of yet.

\section{Future Directions and Conclusions}

Advanced imaging for characterization of carotid plaque vulnerability is useful for the identification of stroke risk. Our current reliance on degree of stenosis has clear limitations that can be overcome by the use of imaging for plaque characterization. Good clinical examples are the estimation of stroke risk in asymptomatic patients with high-grade carotid stenosis and in symptomatic patients with moderate or mild stenosis ipsilateral to the symptomatic territory. In these instances, advanced imaging for plaque characterization can help refine risk stratification and allow for individualization of care.

Future studies comparing different modalities of plaque imaging can be useful, but it is likely that a strategy combining more than one technique will prove most valuable, as some techniques offer complementary information. Cost-effectiveness studies will also need to be conducted. Several small clinical studies have used advanced imaging for plaque characterization to guide therapy (selecting candidates for medical treatment or revascularization, moni- 
toring patients on medical therapy), but large multicenter trials are needed to determine whether plaque imaging can be superior to using only degree of stenosis for selecting candidates for invasive therapy.

\section{References}

1. Ajduk M, Pavić L, Bulimbasić S, Sarlija M, Pavić P, Patrlj $\mathrm{L}$, et al: Multidetector-row computed tomography in evaluation of atherosclerotic carotid plaques complicated with intraplaque hemorrhage. Ann Vasc Surg 23:186-193, 2009

2. Aldemir E, Apaydin M, Varer M, Uluc E: Echolucency of carotid plaques and cerebrovascular events. J Clin Ultrasound 40:399-404, 2012

3. Altaf N, Daniels L, Morgan PS, Auer D, MacSweeney ST, Moody AR, et al: Detection of intraplaque hemorrhage by magnetic resonance imaging in symptomatic patients with mild to moderate carotid stenosis predicts recurrent neurological events. J Vasc Surg 47:337-342, 2008

4. Anzidei M, Napoli A, Geiger D, Cavallo Marincola B, Zini $\mathrm{C}$, Zaccagna F, et al: Preliminary experience with MRA in evaluating the degree of carotid stenosis and plaque morphology using high-resolution sequences after gadofosveset trisodium (Vasovist) administration: comparison with CTA and DSA. Radiol Med (Torino) 115:634-647, 2010

5. Arnold JA, Modaresi KB, Thomas N, Taylor PR, Padayachee TS: Carotid plaque characterization by duplex scanning: observer error may undermine current clinical trials. Stroke 30:61-65, 1999

6. Ballotta E, Angelini A, Mazzalai F, Piatto G, Toniato A, Baracchini C: Carotid endarterectomy for symptomatic lowgrade carotid stenosis. J Vasc Surg 59:25-31, 2014

7. Barger AC, Beeuwkes R III, Lainey LL, Silverman KJ: Hypothesis: vasa vasorum and neovascularization of human coronary arteries. A possible role in the pathophysiology of atherosclerosis. N Engl J Med 310:175-177, 1984

8. Barnett HJ, Taylor DW, Eliasziw M, Fox AJ, Ferguson GG, Haynes RB, et al: Benefit of carotid endarterectomy in patients with symptomatic moderate or severe stenosis. $\mathbf{N}$ Engl J Med 339:1415-1425, 1998

9. Beer AJ, Pelisek J, Heider P, Saraste A, Reeps C, Metz S, et al: PET/CT imaging of integrin $\alpha v \beta 3$ expression in human carotid atherosclerosis. JACC Cardiovasc Imaging 7: 178-187, 2014

10. Blomberg BA, Thomassen A, Takx RA, Hildebrandt MG, Simonsen JA, Buch-Olsen KM, et al: Delayed ${ }^{18} \mathrm{~F}$-fluorodeoxyglucose PET/CT imaging improves quantitation of atherosclerotic plaque inflammation: results from the CAMONA study. J Nucl Cardiol 21:588-597, 2014

11. Calcagno C, Ramachandran S, Izquierdo-Garcia D, Mani V, Millon A, Rosenbaum D, et al: The complementary roles of dynamic contrast-enhanced MRI and 18F-fluorodeoxyglucose PET/CT for imaging of carotid atherosclerosis. Eur J Nucl Med Mol Imaging 40:1884-1893, 2013

12. Cappendijk VC, Cleutjens KB, Heeneman S, Schurink GW, Welten RJ, Kessels AG, et al: In vivo detection of hemorrhage in human atherosclerotic plaques with magnetic resonance imaging. J Magn Reson Imaging 20:105-110, 2004

13. Cappendijk VC, Kessels AG, Heeneman S, Cleutjens KB, Schurink GW, Welten RJ, et al: Comparison of lipid-rich necrotic core size in symptomatic and asymptomatic carotid atherosclerotic plaque: Initial results. J Magn Reson Imaging 27:1356-1361, 2008

14. Carr SC, Farb A, Pearce WH, Virmani R, Yao JS: Activated inflammatory cells are associated with plaque rupture in carotid artery stenosis. Surgery 122:757-764, 1997

15. Chan JM, Monaco C, Wylezinska-Arridge M, Tremoleda JL, Gibbs RG: Imaging of the vulnerable carotid plaque: biological targeting of inflammation in atherosclerosis using iron oxide particles and MRI. Eur J Vasc Endovasc Surg 47:462-469, 2014

16. Chen W, Dilsizian V: Targeted PET/CT imaging of vulnerable atherosclerotic plaques: microcalcification with sodium fluoride and inflammation with fluorodeoxyglucose. Curr Cardiol Rep 15:364, 2013

17. Chu B, Kampschulte A, Ferguson MS, Kerwin WS, Yarnykh VL, O'Brien KD, et al: Hemorrhage in the atherosclerotic carotid plaque: a high-resolution MRI study. Stroke 35: 1079-1084, 2004

18. Clevert DA, Sommer WH, Helck A, Saam T, Reiser M: Improved carotid atherosclerotic plaques imaging with contrast-enhanced ultrasound (CEUS). Clin Hemorheol Microcirc 48:141-148, 2011

19. Coli S, Magnoni M, Sangiorgi G, Marrocco-Trischitta MM, Melisurgo G, Mauriello A, et al: Contrast-enhanced ultrasound imaging of intraplaque neovascularization in carotid arteries: correlation with histology and plaque echogenicity. J Am Coll Cardiol 52:223-230, 2008

20. Das M, Braunschweig T, Mühlenbruch G, Mahnken AH, Krings T, Langer S, et al: Carotid plaque analysis: comparison of dual-source computed tomography (CT) findings and histopathological correlation. Eur J Vasc Endovasc Surg 38:14-19, 2009

21. Della-Morte D, Moussa I, Elkind MS, Sacco RL, Rundek $\mathrm{T}$ : The short-term effect of atorvastatin on carotid plaque morphology assessed by computer-assisted gray-scale densitometry: a pilot study. Neurol Res 33:991-994, 2011

22. den Hartog AG, Bovens SM, Koning W, Hendrikse J, Luijten PR, Moll FL, et al: Current status of clinical magnetic resonance imaging for plaque characterisation in patients with carotid artery stenosis. Eur J Vasc Endovasc Surg 45:7-21, 2013

23. Deyama J, Nakamura T, Takishima I, Fujioka D, Kawabata $\mathrm{K}$, Obata JE, et al: Contrast-enhanced ultrasound imaging of carotid plaque neovascularization is useful for identifying high-risk patients with coronary artery disease. Circ J 77:1499-1507, 2013

24. Droste DW, Jürgens R, Nabavi DG, Schuierer G, Weber S, Ringelstein EB: Echocontrast-enhanced ultrasound of extracranial internal carotid artery high-grade stenosis and occlusion. Stroke 30:2302-2306, 1999

25. Eliasziw M, Streifler JY, Fox AJ, Hachinski VC, Ferguson GG, Barnett HJ: Significance of plaque ulceration in symptomatic patients with high-grade carotid stenosis. North American Symptomatic Carotid Endarterectomy Trial. Stroke 25:304-308, 1994

26. Etesami M, Hoi Y, Steinman DA, Gujar SK, Nidecker AE, Astor BC, et al: Comparison of carotid plaque ulcer detection using contrast-enhanced and time-of-flight MRA techniques. AJNR Am J Neuroradiol 34:177-184, 2013

27. European Carotid Surgery Trialists' Collaborative Group: Randomised trial of endarterectomy for recently symptomatic carotid stenosis: final results of the MRC European Carotid Surgery Trial (ECST). Lancet 351:1379-1387, 1998

28. Fairhead JF, Rothwell PM: The need for urgency in identification and treatment of symptomatic carotid stenosis is already established. Cerebrovasc Dis 19:355-358, 2005

29. Falk E: Why do plaques rupture? Circulation 86 (6 Suppl):III30-III42, 1992

30. Ferrer JM, Samsó JJ, Serrando JR, Valenzuela VF, Montoya SB, Docampo MM: Use of ultrasound contrast in the diagnosis of carotid artery occlusion. J Vasc Surg 31:736-741, 2000

31. Folco EJ, Sheikine Y, Rocha VZ, Christen T, Shvartz E, Sukhova GK, et al: Hypoxia but not inflammation augments glucose uptake in human macrophages: Implications for 
imaging atherosclerosis with 18fluorine-labeled 2-deoxy-Dglucose positron emission tomography. J Am Coll Cardiol 58:603-614, 2011

32. Freilinger TM, Schindler A, Schmidt C, Grimm J, Cyran C, Schwarz F, et al: Prevalence of nonstenosing, complicated atherosclerotic plaques in cryptogenic stroke. JACC Cardiovasc Imaging 5:397-405, 2012

33. Gaens ME, Backes WH, Rozel S, Lipperts M, Sanders SN, Jaspers K, et al: Dynamic contrast-enhanced MR imaging of carotid atherosclerotic plaque: model selection, reproducibility, and validation. Radiology 266:271-279, 2013

34. Glagov S, Weisenberg E, Zarins CK, Stankunavicius R, Kolettis GJ: Compensatory enlargement of human atherosclerotic coronary arteries. N Engl J Med 316:1371-1375, 1987

35. Griswold MA, Jakob PM, Heidemann RM, Nittka M, Jellus V, Wang J, et al: Generalized autocalibrating partially parallel acquisitions (GRAPPA). Magn Reson Med 47:12021210,2002

36. Gupta A, Baradaran H, Schweitzer AD, Kamel H, Pandya A, Delgado D, et al: Carotid plaque MRI and stroke risk: a systematic review and meta-analysis. Stroke 44:3071-3077, 2013

37. Halliday A, Mansfield A, Marro J, Peto C, Peto R, Potter $\mathrm{J}$, et al: Prevention of disabling and fatal strokes by successful carotid endarterectomy in patients without recent neurological symptoms: randomised controlled trial. Lancet 363:1491-1502, 2004

38. Handa N, Matsumoto M, Maeda H, Hougaku H, Kamada $\mathrm{T}$ : Ischemic stroke events and carotid atherosclerosis. Results of the Osaka Follow-up Study for Ultrasonographic Assessment of Carotid Atherosclerosis (the OSACA Study). Stroke 26: 1781-1786, 1995

39. Heidemann RM, Griswold MA, Haase A, Jakob PM: VD-AUTO-SMASH imaging. Magn Reson Med 45:10661074, 2001

40. Hermann S, Starsichova A, Waschkau B, Kuhlmann M, Wenning $\mathrm{C}$, Schober O, et al: Non-FDG imaging of atherosclerosis: will imaging of MMPs assess plaque vulnerability? J Nucl Cardiol 19:609-617, 2012

41. Hobson RW II, Weiss DG, Fields WS, Goldstone J, Moore WS, Towne JB, et al: Efficacy of carotid endarterectomy for asymptomatic carotid stenosis. N Engl J Med 328:221227, 1993

42. Horie N, Morikawa M, Ishizaka S, Takeshita T, So G, Hayashi K, et al: Assessment of carotid plaque stability based on the dynamic enhancement pattern in plaque components with multidetector CT angiography. Stroke 43:393-398, 2012

43. Huang PT, Huang FG, Zou CP, Sun HY, Tian XQ, Yang $Y$, et al: Contrast-enhanced sonographic characteristics of neovascularization in carotid atherosclerotic plaques. J Clin Ultrasound 36:346-351, 2008

44. Jaipersad AS, Shantsila A, Silverman S, Lip GY, Shantsila E: Evaluation of carotid plaque neovascularization using contrast ultrasound. Angiology 64:447-450, 2013

45. Jonasson L, Holm J, Skalli O, Bondjers G, Hansson GK: Regional accumulations of $\mathrm{T}$ cells, macrophages, and smooth muscle cells in the human atherosclerotic plaque. Arteriosclerosis 6:131-138, 1986

46. Joshi NV, Vesey AT, Williams MC, Shah AS, Calvert PA, Craighead FH, et al: $18 \mathrm{~F}$-fluoride positron emission tomography for identification of ruptured and high-risk coronary atherosclerotic plaques: a prospective clinical trial. Lancet 383:705-713, 2014

47. Kadoglou NP, Sailer N, Moumtzouoglou A, Kapelouzou A, Gerasimidis T, Liapis CD: Aggressive lipid-lowering is more effective than moderate lipid-lowering treatment in carotid plaque stabilization. J Vasc Surg 51:114-121, 2010
48. Kern R, Szabo K, Hennerici M, Meairs S: Characterization of carotid artery plaques using real-time compound B-mode ultrasound. Stroke 35:870-875, 2004

49. Kerwin WS, Oikawa M, Yuan C, Jarvik GP, Hatsukami TS: MR imaging of adventitial vasa vasorum in carotid atherosclerosis. Magn Reson Med 59:507-514, 2008

50. Kim HS, Woo JS, Kim BY, Jang HH, Hwang SJ, Kwon SJ, et al: Biochemical and clinical correlation of intraplaque neovascularization using contrast-enhanced ultrasound of the carotid artery. Atherosclerosis 233:579-583, 2014

51. Kirsch JD, Mathur M, Johnson MH, Gowthaman G, Scoutt LM: Advances in transcranial Doppler US: imaging ahead. Radiographics 33:E1-E14, 2013

52. Kurata M, Nose M, Shimazu Y, Aoba T, Kohada Y, Yorioka S, et al: Microvasculature of carotid atheromatous plaques: hemorrhagic plaques have dense microvessels with fenestrations to the arterial lumen. J Stroke Cerebrovasc Dis 23:1440-1446, 2014

53. Kwee RM, Truijman MT, Mess WH, Teule GJ, ter Berg JW, Franke CL, et al: Potential of integrated [18F] fluorodeoxyglucose positron-emission tomography/CT in identifying vulnerable carotid plaques. AJNR Am J Neuroradiol 32:950-954, 2011

54. Kyriacou EC, Pattichis C, Pattichis M, Loizou C, Christodoulou C, Kakkos SK, et al: A review of noninvasive ultrasound image processing methods in the analysis of carotid plaque morphology for the assessment of stroke risk. IEEE Trans Inf Technol Biomed 14:1027-1038, 2010

55. Leschka S, Scheffel H, Desbiolles L, Plass A, Gaemperli O, Valenta I, et al: Image quality and reconstruction intervals of dual-source CT coronary angiography: recommendations for ECG-pulsing windowing. Invest Radiol 42:543-549, 2007

56. Lindner JR, Dayton PA, Coggins MP, Ley K, Song J, Ferrara K, et al: Noninvasive imaging of inflammation by ultrasound detection of phagocytosed microbubbles. Circulation 102:531-538, 2000

57. Markus HS, Brown MM: Differentiation between different pathological cerebral embolic materials using transcranial Doppler in an in vitro model. Stroke 24:1-5, 1993

58. Marnane M, Merwick A, Sheehan OC, Hannon N, Foran P, Grant T, et al: Carotid plaque inflammation on 18F-fluorodeoxyglucose positron emission tomography predicts early stroke recurrence. Ann Neurol 71:709-718, 2012

59. Masteling MG, Zeebregts CJ, Tio RA, Breek JC, Tietge UJ, de Boer JF, et al: High-resolution imaging of human atherosclerotic carotid plaques with micro 18F-FDG PET scanning exploring plaque vulnerability. J Nucl Cardiol 18:1066-1075, 2011

60. Mathiesen EB, Bønaa KH, Joakimsen O: Echolucent plaques are associated with high risk of ischemic cerebrovascular events in carotid stenosis: the Troms $\varnothing$ study. Circulation 103:2171-2175, 2001

61. Menezes LJ, Kotze CW, Agu O, Richards T, Brookes J, Goh VJ, et al: Investigating vulnerable atheroma using combined (18)F-FDG PET/CT angiography of carotid plaque with immunohistochemical validation. J Nucl Med 52:1698-1703, 2011

62. Michel JB, Delbosc S, Ho-Tin-Noé B, Leseche G, Nicoletti A, Meilhac O, et al: From intraplaque haemorrhages to plaque vulnerability: biological consequences of intraplaque haemorrhages. J Cardiovasc Med (Hagerstown) 13:628634, 2012

63. Milei J, Parodi JC, Fernandez Alonso G, Barone A, Beigelman R, Ferreira LM, et al: Carotid atherosclerosis. Immunocytochemical analysis of the vascular and cellular composition in endarterectomies. Cardiologia 41:535-542, 1996 
64. Millon A, Boussel L, Brevet M, Mathevet JL, Canet-Soulas E, Mory C, et al: Clinical and histological significance of gadolinium enhancement in carotid atherosclerotic plaque. Stroke 43:3023-3028, 2012

65. Mizoguchi M, Tahara N, Tahara A, Nitta Y, Kodama N, Oba T, et al: Pioglitazone attenuates atherosclerotic plaque inflammation in patients with impaired glucose tolerance or diabetes a prospective, randomized, comparator-controlled study using serial FDG PET/CT imaging study of carotid artery and ascending aorta. JACC Cardiovasc Imaging 4:1110-1118, 2011

66. Moustafa RR, Izquierdo-Garcia D, Fryer TD, Graves MJ, Rudd JH, Gillard JH, et al: Carotid plaque inflammation is associated with cerebral microembolism in patients with recent transient ischemic attack or stroke: a pilot study. Circ Cardiovasc Imaging 3:536-541, 2010

67. Mughal MM, Khan MK, DeMarco JK, Majid A, Shamoun F, Abela GS: Symptomatic and asymptomatic carotid artery plaque. Expert Rev Cardiovasc Ther 9:1315-1330, 2011

68. Müller A, Beck K, Rancic Z, Müller C, Fischer CR, Betzel $\mathrm{T}$, et al: Imaging atherosclerotic plaque inflammation via folate receptor targeting using a novel $18 \mathrm{~F}$-folate radiotracer. Mol Imaging 13:1-11, 2014

69. Muraki M, Mikami T, Yoshimoto T, Fujimoto S, Tokuda K, Kaneko S, et al: New criteria for the sonographic diagnosis of a plaque ulcer in the extracranial carotid artery. AJR Am J Roentgenol 198:1161-1166, 2012

70. Nakamura T, Tsutsumi Y, Shimizu Y, Uchiyama S: Ulcerated carotid plaques with ultrasonic echolucency are causatively associated with thromboembolic cerebrovascular events. J Stroke Cerebrovasc Dis 22:93-99, 2013

71. Niccoli Asabella A, Ciccone MM, Cortese F, Scicchitano P, Gesualdo M, Zito A, et al: Higher reliability of 18F-FDG target background ratio compared to standardized uptake value in vulnerable carotid plaque detection: a pilot study. Ann Nucl Med 28:571-579, 2014

72. North American Symptomatic Carotid Endarterectomy Trial Collaborators: Beneficial effect of carotid endarterectomy in symptomatic patients with high-grade carotid stenosis. $\mathbf{N}$ Engl J Med 325:445-453, 1991

73. Piscaglia F, Nolsøe C, Dietrich CF, Cosgrove DO, Gilja $\mathrm{OH}, \mathrm{Bachmann}$ Nielsen M, et al: The EFSUMB Guidelines and Recommendations on the Clinical Practice of Contrast Enhanced Ultrasound (CEUS): update 2011 on non-hepatic applications. Ultraschall Med 33:33-59, 2012

74. Qiao Y, Etesami M, Astor BC, Zeiler SR, Trout HH III, Wasserman BA: Carotid plaque neovascularization and hemorrhage detected by MR imaging are associated with recent cerebrovascular ischemic events. AJNR Am J Neuroradiol 33:755-760, 2012

75. Qureshi AI, Alexandrov AV, Tegeler CH, Hobson RW II, Dennis Baker J, Hopkins LN: Guidelines for screening of extracranial carotid artery disease. J Neuroimaging 17:19 47, 2007

76. Reiter M, Horvat R, Puchner S, Rinner W, Polterauer P, Lammer J, et al: Plaque imaging of the internal carotid artery - correlation of B-flow imaging with histopathology. AJNR Am J Neuroradiol 28:122-126, 2007

77. Ritter MA, Dittrich R, Thoenissen N, Ringelstein EB, Nabavi DG: Prevalence and prognostic impact of microembolic signals in arterial sources of embolism. A systematic review of the literature. J Neurol 255:953-961, 2008

78. Ritter MA, Theismann K, Schmiedel M, Ringelstein EB, Dittrich R: Vascularization of carotid plaque in recently symptomatic patients is associated with the occurrence of transcranial microembolic signals. Eur J Neurol 20:12181221,2013

79. Rudd JH, Myers KS, Bansilal S, Machac J, Pinto CA, Tong $\mathrm{C}$, et al: Atherosclerosis inflammation imaging with $18 \mathrm{~F}-$
FDG PET: carotid, iliac, and femoral uptake reproducibility, quantification methods, and recommendations. J Nucl Med 49:871-878, 2008

80. Rudd JH, Myers KS, Bansilal S, Machac J, Rafique A, Farkouh M, et al: (18)Fluorodeoxyglucose positron emission tomography imaging of atherosclerotic plaque inflammation is highly reproducible: implications for atherosclerosis therapy trials. J Am Coll Cardiol 50:892-896, 2007

81. Saam T, Ferguson MS, Yarnykh VL, Takaya N, Xu D, Polissar NL, et al: Quantitative evaluation of carotid plaque composition by in vivo MRI. Arterioscler Thromb Vasc Biol 25:234-239, 2005

82. Saam T, Hatsukami TS, Takaya N, Chu B, Underhill H, Kerwin WS, et al: The vulnerable, or high-risk, atherosclerotic plaque: noninvasive MR imaging for characterization and assessment. Radiology 244:64-77, 2007

83. Saam T, Hetterich H, Hoffmann V, Yuan C, Dichgans M, Poppert H, et al: Meta-analysis and systematic review of the predictive value of carotid plaque hemorrhage on cerebrovascular events by magnetic resonance imaging. J Am Coll Cardiol 62:1081-1091, 2013

84. Saba L, Caddeo G, Sanfilippo R, Montisci R, Mallarini G: $\mathrm{CT}$ and ultrasound in the study of ulcerated carotid plaque compared with surgical results: potentialities and advantages of multidetector row CT angiography. AJNR Am J Neuroradiol 28:1061-1066, 2007

85. Saba L, Caddeo G, Sanfilippo R, Montisci R, Mallarini $\mathrm{G}$ : Efficacy and sensitivity of axial scans and different reconstruction methods in the study of the ulcerated carotid plaque using multidetector-row CT angiography: comparison with surgical results. AJNR Am J Neuroradiol 28:716-723, 2007

86. Saba L, Lai ML, Montisci R, Tamponi E, Sanfilippo R, Faa $\mathrm{G}$, et al: Association between carotid plaque enhancement shown by multidetector CT angiography and histologically validated microvessel density. Eur Radiol 22:2237-2245, 2012

87. Saba L, Mallarini G: Carotid plaque enhancement and symptom correlations: an evaluation by using multidetector row CT angiography. AJNR Am J Neuroradiol 32:19191925,2011

88. Saba L, Mallarini G: Fissured fibrous cap of vulnerable carotid plaques and symptomaticity: are they correlated? Preliminary results by using multi-detector-row CT angiography. Cerebrovasc Dis 27:322-327, 2009

89. Saba L, Tamponi E, Raz E, Lai L, Montisci R, Piga M, et al: Correlation between fissured fibrous cap and contrast enhancement: preliminary results with the use of CTA and histologic validation. AJNR Am J Neuroradiol 35:754759,2014

90. Saito H, Kuroda S, Hirata K, Magota K, Shiga T, Tamaki N, et al: Validity of dual MRI and F-FDG PET imaging in predicting vulnerable and inflamed carotid plaque. Cerebrovasc Dis 35:370-377, 2013

91. Shalhoub J, Monaco C, Owen DR, Gauthier T, Thapar A, Leen EL, et al: Late-phase contrast-enhanced ultrasound reflects biological features of instability in human carotid atherosclerosis. Stroke 42:3634-3636, 2011

92. Sheikine Y, Akram K: FDG-PET imaging of atherosclerosis: Do we know what we see? Atherosclerosis 211:371380,2010

93. Sibley CT, Vavere AL, Gottlieb I, Cox C, Matheson M, Spooner A, et al: MRI-measured regression of carotid atherosclerosis induced by statins with and without niacin in a randomised controlled trial: the NIA plaque study. Heart 99:1675-1680, 2013

94. Silvera SS, Aidi HE, Rudd JH, Mani V, Yang L, Farkouh $\mathrm{M}$, et al: Multimodality imaging of atherosclerotic plaque activity and composition using FDG-PET/CT and MRI in 
carotid and femoral arteries. Atherosclerosis 207:139-143, 2009

95. Singh AS, Atam V, Jain N, Yathish BE, Patil MR, Das L: Association of carotid plaque echogenicity with recurrence of ischemic stroke. N Am J Med Sci 5:371-376, 2013

96. Singh N, Moody AR, Gladstone DJ, Leung G, Ravikumar $\mathrm{R}$, Zhan J, et al: Moderate carotid artery stenosis: MR imaging-depicted intraplaque hemorrhage predicts risk of cerebrovascular ischemic events in asymptomatic men. Radiology 252:502-508, 2009

97. Spence JD, Tamayo A, Lownie SP, Ng WP, Ferguson GG: Absence of microemboli on transcranial Doppler identifies low-risk patients with asymptomatic carotid stenosis. Stroke 36:2373-2378, 2005

98. Spencer MP, Thomas GI, Nicholls SC, Sauvage LR: Detection of middle cerebral artery emboli during carotid endarterectomy using transcranial Doppler ultrasonography. Stroke 21:415-423, 1990

99. Stary HC, Blankenhorn DH, Chandler AB, Glagov S, Insull W Jr, Richardson M, et al: A definition of the intima of human arteries and of its atherosclerosis-prone regions. Circulation 85:391-405, 1992

100. Stary HC, Chandler AB, Dinsmore RE, Fuster V, Glagov S, Insull W Jr, et al: A definition of advanced types of atherosclerotic lesions and a histological classification of atherosclerosis. Circulation 92:1355-1374, 1995

101. Stary HC, Chandler AB, Glagov S, Guyton JR, Insull W Jr, Rosenfeld ME, et al: A definition of initial, fatty streak, and intermediate lesions of atherosclerosis. Circulation 89:2462-2478, 1994

102. Staub D, Patel MB, Tibrewala A, Ludden D, Johnson M, Espinosa P, et al: Vasa vasorum and plaque neovascularization on contrast-enhanced carotid ultrasound imaging correlates with cardiovascular disease and past cardiovascular events. Stroke 41:41-47, 2010

103. Steinberg D, Witztum JL: Lipoproteins and atherogenesis. Current concepts. JAMA 264:3047-3052, 1990

104. Tahara N, Kai H, Ishibashi M, Nakaura H, Kaida H, Baba $\mathrm{K}$, et al: Simvastatin attenuates plaque inflammation: evaluation by fluorodeoxyglucose positron emission tomography. J Am Coll Cardiol 48: 1825-1831, 2006

105. Tawakol A, Fayad ZA, Mogg R, Alon A, Klimas MT, Dansky $\mathrm{H}$, et al: Intensification of statin therapy results in a rapid reduction in atherosclerotic inflammation: results of a multicenter fluorodeoxyglucose-positron emission tomography/computed tomography feasibility study. J Am Coll Cardiol 62:909-917, 2013

106. Tawakol A, Migrino RQ, Bashian GG, Bedri S, Vermylen $\mathrm{D}$, Cury RC, et al: In vivo $18 \mathrm{~F}$-fluorodeoxyglucose positron emission tomography imaging provides a noninvasive measure of carotid plaque inflammation in patients. J Am Coll Cardiol 48: 1818-1824, 2006

107. ten Kate GL, Renaud GG, Akkus Z, van den Oord SC, ten Cate FJ, Shamdasani V, et al: Far-wall pseudoenhancement during contrast-enhanced ultrasound of the carotid arteries: clinical description and in vitro reproduction. Ultrasound Med Biol 38:593-600, 2012

108. ten Kate GL, van den Oord SC, Sijbrands EJ, van der Lugt A, de Jong N, Bosch JG, et al: Current status and future developments of contrast-enhanced ultrasound of carotid atherosclerosis. J Vasc Surg 57:539-546, 2013

109. ten Kate GL, van Dijk AC, van den Oord SC, Hussain B, Verhagen HJ, Sijbrands EJ, et al: Usefulness of contrastenhanced ultrasound for detection of carotid plaque ulceration in patients with symptomatic carotid atherosclerosis. Am J Cardiol 112:292-298, 2013

110. Topakian R, King A, Kwon SU, Schaafsma A, Shipley M, Markus HS: Ultrasonic plaque echolucency and emboli signals predict stroke in asymptomatic carotid stenosis. Neurology 77:751-758, 2011

111. Truijman MT, Kwee RM, van Hoof RH, Hermeling E, van Oostenbrugge RJ, Mess WH, et al: Combined 18F-FDG PET-CT and DCE-MRI to assess inflammation and microvascularization in atherosclerotic plaques. Stroke 44:35683570,2013

112. Underhill HR, Yuan C, Zhao XQ, Kraiss LW, Parker DL, Saam T, et al: Effect of rosuvastatin therapy on carotid plaque morphology and composition in moderately hypercholesterolemic patients: a high-resolution magnetic resonance imaging trial. Am Heart J 155:584.e1-584.e8, 2008

113. van Gils MJ, Vukadinovic D, van Dijk AC, Dippel DW, Niessen WJ, van der Lugt A: Carotid atherosclerotic plaque progression and change in plaque composition over time: a 5-year follow-up study using serial CT angiography. AJNR Am J Neuroradiol 33:1267-1273, 2012

114. van Zuilen EV, Moll FL, Vermeulen FE, Mauser HW, van Gijn J, Ackerstaff RG: Detection of cerebral microemboli by means of transcranial Doppler monitoring before and after carotid endarterectomy. Stroke 26:210-213, 1995

115. Vavuranakis M, Sigala F, Vrachatis DA, Papaioannou TG, Filis K, Kavantzas N, et al: Quantitative analysis of carotid plaque vasa vasorum by CEUS and correlation with histology after endarterectomy. Vasa 42:184-195, 2013

116. Walker MD, Marler JR, Goldstein M, Grady PA, Toole JF, Baker WF, et al: Endarterectomy for asymptomatic carotid artery stenosis. JAMA 273:1421-1428, 1995

117. Watanabe Y, Nagayama M: MR plaque imaging of the carotid artery. Neuroradiology 52:253-274, 2010

118. Watanabe Y, Nagayama M, Suga T, Yoshida K, Yamagata S, Okumura A, et al: Characterization of atherosclerotic plaque of carotid arteries with histopathological correlation: vascular wall MR imaging vs. color Doppler ultrasonography (US). J Magn Reson Imaging 28:478-485, 2008

119. Wilhjelm JE, Jensen MS, Jespersen SK, Sahl B, Falk E: Visual and quantitative evaluation of selected image combination schemes in ultrasound spatial compound scanning. IEEE Trans Med Imaging 23:181-190, 2004

120. Wintermark M, Arora S, Tong E, Vittinghoff E, Lau BC, Chien JD, et al: Carotid plaque computed tomography imaging in stroke and nonstroke patients. Ann Neurol 64:149157,2008

121. Wintermark M, Jawadi SS, Rapp JH, Tihan T, Tong E, Glidden DV, et al: High-resolution CT imaging of carotid artery atherosclerotic plaques. AJNR Am J Neuroradiol 29:875-882, 2008

122. Xiong L, Deng YB, Zhu Y, Liu YN, Bi XJ: Correlation of carotid plaque neovascularization detected by using contrast-enhanced US with clinical symptoms. Radiology 251:583-589, 2009

123. Yim YJ, Choe YH, Ko Y, Kim ST, Kim KH, Jeon P, et al: High signal intensity halo around the carotid artery on maximum intensity projection images of time-of-flight MR angiography: a new sign for intraplaque hemorrhage. J Magn Reson Imaging 27:1341-1346, 2008

124. Yoshida K, Sadamasa N, Narumi O, Chin M, Yamagata S, Miyamoto S: Symptomatic low-grade carotid stenosis with intraplaque hemorrhage and expansive arterial remodeling is associated with a high relapse rate refractory to medical treatment. Neurosurgery 70:1143-1151, 2012

125. Yoshimura S, Yamada K, Kawasaki M, Asano T, Kanematsu M, Miyai M, et al: Selection of carotid artery stenting or endarterectomy based on magnetic resonance plaque imaging reduced periprocedural adverse events. J Stroke Cerebrovasc Dis 22:1082-1087, 2013

126. Yoshimura S, Yamada K, Kawasaki M, Asano T, Kanematsu M, Takamatsu M, et al: High-intensity signal on time-of-flight magnetic resonance angiography indicates 
carotid plaques at high risk for cerebral embolism during stenting. Stroke 42:3132-3137, 2011

127. Yuan C, Mitsumori LM, Ferguson MS, Polissar NL, Echelard D, Ortiz G, et al: In vivo accuracy of multispectral magnetic resonance imaging for identifying lipid-rich necrotic cores and intraplaque hemorrhage in advanced human carotid plaques. Circulation 104:2051-2056, 2001

128. Zhao XQ, Dong L, Hatsukami T, Phan BA, Chu B, Moore A, et al: MR imaging of carotid plaque composition during lipid-lowering therapy a prospective assessment of effect and time course. JACC Cardiovasc Imaging 4:977-986, 2011

129. Zhou Y, Xing Y, Li Y, Bai Y, Chen Y, Sun X, et al: An assessment of the vulnerability of carotid plaques: a comparative study between intraplaque neovascularization and plaque echogenicity. BMC Med Imaging 13:13, 2013

130. Zhu Y, Deng YB, Liu YN, Bi XJ, Sun J, Tang QY, et al: Use of carotid plaque neovascularization at contrast- enhanced US to predict coronary events in patients with coronary artery disease. Radiology 268:54-60, 2013

\section{Author Contributions}

Conception and design: Brinjikji, Huston, Rabinstein, Lerman, Lanzino. Analysis and interpretation of data: Brinjikji, Lanzino. Drafting the article: Brinjikji, Rabinstein, Lanzino. Critically revising the article: all authors. Reviewed submitted version of manuscript: all authors. Approved the final version of the manuscript on behalf of all authors: Brinjikji. Administrative/technical/ material support: Brinjikji, Rabinstein, Kim, Lerman, Lanzino. Study supervision: Huston, Rabinstein, Lanzino.

\section{Correspondence}

Waleed Brinjikji, Department of Radiology, Mayo Clinic, 200 1st St. SW, Rochester, MN 55905. email: brinjikji.waleed@mayo. edu. 